\title{
Random Movement of Mesoscale Eddies in the Global Ocean
}

\author{
QINBIAO NI \\ College of Ocean and Earth Sciences, Xiamen University, Xiamen, China \\ XIAOMING ZHAI \\ Centre for Ocean and Atmospheric Sciences, School of Environmental Sciences, University of East Anglia, Norwich, \\ United Kingdom \\ GUIHUA WANG \\ Department of Atmospheric and Oceanic Sciences and Institute of Atmospheric Sciences, Fudan University, Shanghai, China \\ DAVID P. MARSHALL \\ Department of Physics, University of Oxford, Oxford, United Kingdom
}

(Manuscript received 12 August 2019, in final form 12 June 2020)

\begin{abstract}
In this study we track and analyze eddy movement in the global ocean using 20 years of altimeter data and show that, in addition to the well-known westward propagation and slight polarity-based meridional deflections, mesoscale eddies also move randomly in all directions at all latitudes as a result of eddy-eddy interaction. The speed of this random eddy movement decreases with latitude and equals the baroclinic Rossby wave speed at about $25^{\circ}$ of latitude. The tracked eddies are on average isotropic at mid- and high latitudes, but become noticeably more elongated in the zonal direction at low latitudes. Our analyses suggest a critical latitude of approximately $25^{\circ}$ that separates the global ocean into a low-latitude anisotropic wavelike regime and a high-latitude isotropic turbulence regime. One important consequence of random eddy movement is that it results in lateral diffusion of eddy energy. The associated eddy energy diffusivity, estimated using two different methods, is found to be a function of latitude. The zonal-mean eddy energy diffusivity varies from over $1500 \mathrm{~m}^{2} \mathrm{~s}^{-1}$ at low latitudes to around $500 \mathrm{~m}^{2} \mathrm{~s}^{-1}$ at high latitudes, but significantly larger values are found in the eddy energy hotspots at all latitudes, in excess of $5000 \mathrm{~m}^{2} \mathrm{~s}^{-1}$. Results from this study have important implications for recently developed energetically consistent mesoscale eddy parameterization schemes which require solving the eddy energy budget.
\end{abstract}

\section{Introduction}

Mesoscale eddies are ubiquitous and energetic features of the global ocean circulation and play an important role in transporting climatically important properties such as mass, heat, carbon, and nutrients (Richardson 1983; Chelton et al. 2011; Zhai et al. 2010; Zhang et al. 2014; Dong et al. 2014; Conway et al. 2018). The magnitudes of eddy tracer transports depend on the eddy diffusivities, which are believed to scale with the eddy energy (e.g., Eden and Greatbatch 2008; Marshall and Adcroft 2010; Marshall et al. 2012; Jansen and Held 2014; Jansen et al. 2015; Mak et al. 2018) which, in turn, is dominated by the

Corresponding author: Xiaoming Zhai, xiaoming.zhai@uea.ac.uk largest scale eddies, due to the inverse energy cascade (e.g., Ferrari and Wunsch 2010). Therefore, to understand eddy transports and their impact on the global tracer and energy budgets, a key step is to understand the distribution of eddy energy and the processes that move the largest eddies around the ocean.

It is well known that, owing to the $\beta$ effect, eddy movement in the ocean is strongly anisotropic. In the zonal direction, apart from in the Antarctic Circumpolar Current and separated western boundary currents, mesoscale eddies are found to propagate ubiquitously westward at speeds close to the long baroclinic Rossby wave, varying from over $20 \mathrm{~cm} \mathrm{~s}^{-1}$ near the equator to less than $1 \mathrm{~cm} \mathrm{~s}^{-1}$ near the polar regions (Chelton et al. 2007, 2011; Hughes and Miller 2017). In the meridional 
direction, anticyclonic eddies and cyclonic eddies tend to drift slightly equatorward and poleward, respectively, as a result of combined effects of $\beta$ and self-advection (Cushman-Roisin et al. 1990; Chassignet and CushmanRoisin 1991; Morrow et al. 2004). These characteristics of eddy movement are particularly clearly observed for isolated eddies (McWilliams and Flierl 1979; Early et al. 2011).

The ocean, on the other hand, is crowded with nonlinear eddies, where eddy distortion, coupling, splitting, and merging occur all the time. This eddy-eddy interaction potentially changes eddy pathways, making them deviate from the simple picture of westward propagation plus meridional deflection (Early et al. 2011). For example, recent idealized modeling studies have shown that eddies can strongly interact with each other which leads to isotropic eddy energy spread from the source region on an $f$ plane (Grooms 2015, 2017). To our knowledge, so far there have been no systematic studies of such random eddy movement due to eddy-eddy interaction in the global ocean from observations.

The $\beta$ effect also induces another anisotropy in ocean eddies, that is, different eddy length scales in the zonal and meridional directions. In the inverse cascade theory of geostrophic turbulence, as the eddies grow in size through nonlinear interaction, their time scale increases. When the eddy time scale matches the time scale of Rossby waves, Rossby waves may be excited and turbulent eddy energy is transformed into Rossby waves or zonally elongated flow (Rhines 1975; Tulloch et al. 2009). Generally, this transition from turbulence to waves occurs only at low latitudes where turbulence and Rossby wave time scales overlap. In contrast, at high latitudes Rossby wave frequencies are too low to be excited by turbulent eddies in the inverse cascade process. As such, there exists a critical latitude that separates the global ocean into a low-latitude anisotropic wavelike regime and a high-latitude isotropic turbulence regime (Theiss 2004; Eden 2007; Tulloch et al. 2009; Klocker and Abernathey 2014; Klocker et al. 2016). The critical latitude is often defined as the latitude at which the Rhines length scale equals Rossby deformation radius or the latitude at which the eddy rotational speed equals Rossby wave propagation speed, and is diagnosed to be in the range of $18^{\circ}-30^{\circ}$ depending on the data and method used (Eden 2007; Tulloch et al. 2009; Klocker and Abernathey 2014). Whether and how the different regimes at low and high latitudes affect random eddy movement associated with eddy-eddy interaction are yet open questions.

One important consequence of random eddy movement is that it results in lateral diffusion of eddy energy. Ocean models used for long-range climate simulations will reply on parameterizing the effect of mesoscale eddies for the foreseeable future. State-of-the-art eddy parameterization schemes solve an explicit eddy energy budget to control the magnitude of eddy transfer coefficients (e.g., Eden and Greatbatch 2008; Marshall and Adcroft 2010; Marshall et al. 2012; Jansen and Held 2014; Jansen et al. 2015; Mak et al. 2018). One of the unknowns in this eddy energy budget is the lateral eddy energy diffusion coefficient whose value is sometimes chosen for numerical reasons (Mak et al. 2018). Since the eddy energy is dominated by coherent eddies at the largest scales due to the inverse energy cascade, in this study, we track and analyze random movement of dynamically coherent mesoscale eddies in the global ocean using satellite altimeter data and provide an estimate of associated eddy energy diffusivity.

The paper is organized as follows. Mesoscale eddy trajectories tracked from the satellite-derived sea level anomaly (SLA) data are analyzed in section 2, eddy movement speeds calculated from these trajectories are described in section 3, and eddy length scales in the zonal and meridional directions are compared in section 4. In section 5 we conduct stochastically forced quasigeostrophic (QG) reduced-gravity model experiments to help interpret some observed behavior of random eddy movement and in section 6 we estimate eddy energy diffusivity associated with random eddy movement using two different methods. Finally, conclusions are provided in section 7 .

\section{Eddy trajectory}

Daily gridded global SLA data produced and distributed by the Copernicus Marine Environment Monitoring Service (http://marine.copernicus.eu/) are used in this study for the 20-yr period from January 1998 to December 2017. This SLA data product merges the Ocean Topography Experiment (TOPEX)/Poseidon, Jason-1, ERS-1/2, and Envisat altimetry measurements onto a $0.25^{\circ} \times 0.25^{\circ}$ grid. To remove large-scale signals associated with wind forcing and surface heating/cooling and isolate mesoscale variability, each SLA map is high-pass filtered using a Gaussian function with a half-power cutoff wavelength of $10^{\circ}$ before we apply the eddy detection and tracking procedure (Xu et al. 2016).

The eddy identification method we employ here is based on the SLA geometry (e.g., Chelton et al. 2011; Chaigneau et al. 2011). Contours are first extracted from the high-pass-filtered SLA maps at an interval of $1 \mathrm{~cm}$ (Chelton et al. 2011). Then, the average position of the innermost closed SLA contour is regarded as the center of an eddy, the outermost closed SLA contour that encloses no more than one eddy center is regarded as the 


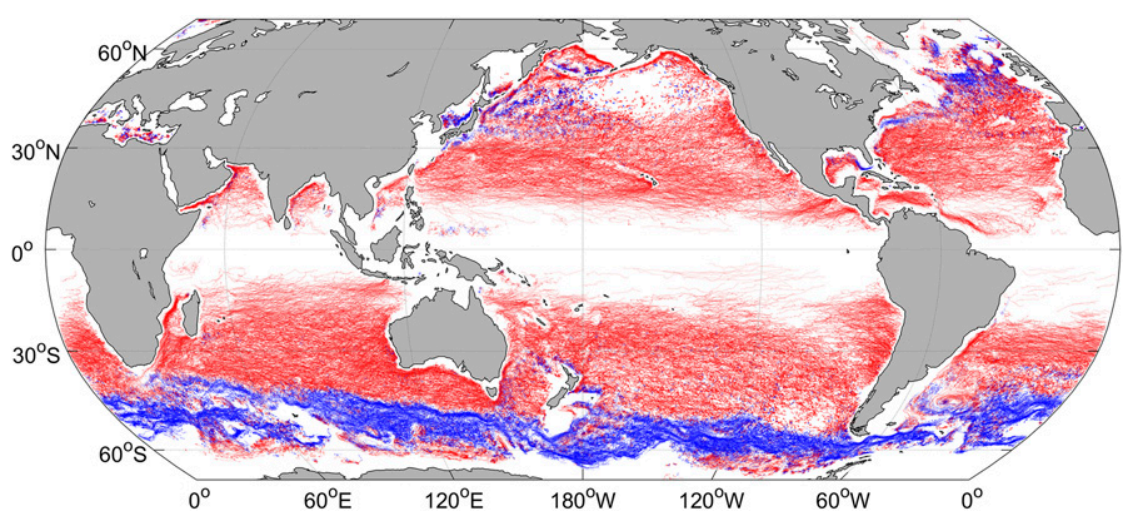

FIG. 1. Mesoscale eddy trajectories tracked in the global ocean over the 20 -yr period from 1998 to 2017. Only trajectories longer than 90 days are shown and the trajectories with initial locations east (west) to terminal locations are plotted in red (blue).

edge of the eddy and the SLA difference between the eddy center and the eddy edge is taken to be the amplitude of the eddy. The radius of the eddy is defined as the radius of a circle that has the same area as that within the outermost closed SLA contour. Given the accuracy of satellite altimetry data, eddies with amplitude smaller than $3 \mathrm{~cm}$ are excluded (Chaigneau et al. 2011) in our analysis. Eddies are tracked by finding the smallest dissimilarity parameter $\Delta$ (e.g., Penven et al. 2005; Souza et al. 2011) from time step $i$ to time step $i+1$ within a search circle centered at the eddy center at time step $i$ :

$$
\Delta=\sqrt{\left(\frac{r^{i+1}-r^{i}}{r^{i}}\right)^{2}+\left(\frac{\eta_{0}^{i+1}-\eta_{0}^{i}}{\eta_{0}^{i}}\right)^{2}},
$$

where $r$ is the radius of the eddy, and $\eta_{0}$ is the SLA at the center of the eddy. Given that the distance between two eddy centers identified from altimeter data is typically larger than $80 \mathrm{~km}$ (Chelton et al. 2011) and that no eddies travel longer than $80 \mathrm{~km}$ in one day, the radius of a search circle is set to be $80 \mathrm{~km}$. The eddy tracking automatically terminates when eddies are no longer found within the search circle. An alternative eddy detection and tracking method of finding the closest centroid of the eddy edge (Chelton et al. 2011) is also used and the results are almost identical (see appendix A; Fig. A1).

Using the eddy identification and tracking procedure described above, nearly 1200000 trajectories of mesoscale eddies are tracked from the SLA maps during the 20-yr study period. For clarity, only eddy trajectories with lifespan longer than 3 months are shown in Fig. 1. Comparing eddy terminal locations with their initial locations, these long-lived eddies are found to propagate predominantly westward in the global ocean, apart from in the Kuroshio, Gulf Stream, and Antarctic Circumpolar Current regions where they are advected eastward by strong depth-mean flow, consistent with previous studies (e.g., Chelton et al. 2011; Klocker and Marshall 2014).

We now group together the long-lived eddy tracks that originate poleward and equatorward of the latitude of $25^{\circ}$ separately. There are two reasons for choosing this latitude. First, it is the critical latitude found by Tulloch et al. (2009) that separates the low-latitude anisotropic wavelike regime and high-latitude isotropic turbulence regime. Second, our analysis later also identifies this latitude to be the latitude at which the eddy random movement speed equals Rossby wave propagation speed and the latitude equatorward of which the eddy zonal length scale starts to significantly exceed its meridional length scale (see sections 3 and 4 ). As shown in Fig. 2a, equatorward of $25^{\circ}$ in latitude, the identified eddies propagate predominately westward with slight poleward and equatorward deflection for cyclonic and anticyclonic eddies, respectively. This result is consistent with two previous ocean eddy census studies (Chelton et al. 2007, 2011). However, poleward of $25^{\circ}$, a different picture emerges. Westward propagation becomes much less dominant and a large percentage of eddies move eastward, northward, and southward (Fig. 2b). On closer inspection, these eddy trajectories are found to be convoluted and often characterized by a large number of looping structures, reflecting complex eddy-eddy interaction in the real ocean. Similar random eddy movement has also been found in recent idealized model simulations where eddy-eddy interaction leads to lateral spreading of eddies from their source regions (Grooms 2015, 2017). In the next section, we use the tracked eddy trajectories to further quantify the random eddy movement speeds. 


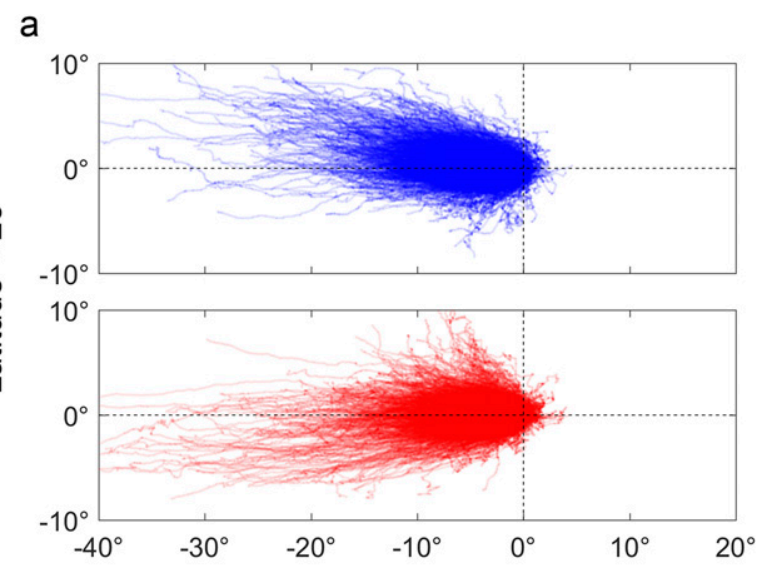

b

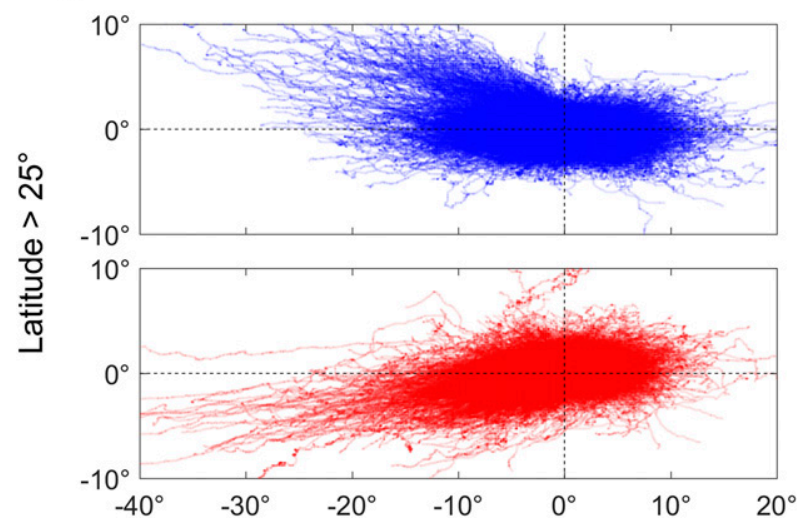

FIG. 2. (a) Anticyclonic (red) and cyclonic (blue) eddy tracks ( $>90$ days) originated equatorward of $25^{\circ}$ latitude, relative to the initial locations, with the positive $x$ and $y$ axis corresponding to eastward and poleward, respectively. (b) As in (a), but for the eddy tracks originated poleward of $25^{\circ}$.

\section{Eddy movement speed}

When it comes to characterizing eddy movement, one of the most commonly used metrics is the timemean zonal eddy movement velocity, that is, the Eulerian time average of the zonal (eastward and westward) velocity component at which the eddies propagate. Here we compare the magnitude of zonal eddy movement velocity with the absolute eddy movement speed defined as the distance traveled by the eddies divided by the time elapsed which is one day, i.e., temporal resolution of altimeter data. With all the eddy trajectories tracked in the $20-\mathrm{yr}$ period, it is straightforward to calculate these two quantities and then project and average them onto a global $2.5^{\circ} \times$ $2.5^{\circ}$ grid. Except in the separated boundary currents, the zonal eddy movement velocities are predominantly westward and are slightly smaller than the phase speeds of the Rossby wave (Figs. 3a,b), same as earlier results (Chelton et al. 2007, 2011; Tulloch et al.
2009). The absolute eddy movement speeds are considerably larger than the magnitude of zonal eddy movement velocities almost everywhere in the global ocean, and also larger than the Rossby wave speeds outside of the tropics (Figs. 3c,d). This result is again characteristic of random eddy movement in the ocean. Since eddies travel in all directions, the calculation of zonal eddy movement velocity involves cancellation of westward and eastward eddy propagation velocities which contributes to the smaller magnitude of zonal eddy movement velocities compared to the absolute eddy movement speeds.

To test this conjecture, we calculate eddy movement speeds in all four directions. For example, the northward eddy movement speed is defined as the distance traveled by the eddies in the northward direction divided by the time elapsed (one day). A few interesting features emerge (Fig. 4). First, eddy movement speeds in all four directions decrease quickly with increasing latitude at low latitudes and remain roughly constant, at approximately $4.5 \mathrm{~cm} \mathrm{~s}^{-1}$, at high latitudes. There is also indication that random eddy movement speeds are slightly elevated in eddyrich regions such as the western boundary current regions. Second, eddy movement speeds are isotropic at mid- and high latitudes, but anisotropic at low latitudes. At low latitudes, the northward and southward eddy movement speeds are almost identical and both are noticeably smaller than the eastward eddy movement speed which is, in turn, much smaller than the westward eddy movement speed. Third, the meridional eddy movement speeds equal the Rossby wave speeds at about $25^{\circ}$ in latitude. Note that this is also the latitude at which the magnitude of previously estimated depth-averaged eddy velocities matches the Rossby wave speed (Tulloch et al. 2009). It is perhaps not surprising that the random eddy movement speeds and depth-averaged eddy velocities are related since random eddy movement is induced by eddy-eddy interaction.

The number of times that eddies are detected to move in each of the four directions relative to their locations on the previous day is of the same order of magnitude (thousands of times in each case), although westward movements occur more frequently than eastward movements apart from the Antarctic Circumpolar Current latitudes (Fig. 5). Further analyses show that there is almost no difference in eddy movement speeds in all four directions between anticyclones and cyclones (Fig. 6). It is worth pointing out that the eddy movement speeds diagnosed in our study are more than one order of magnitude larger than those associated with equatorward (poleward) 

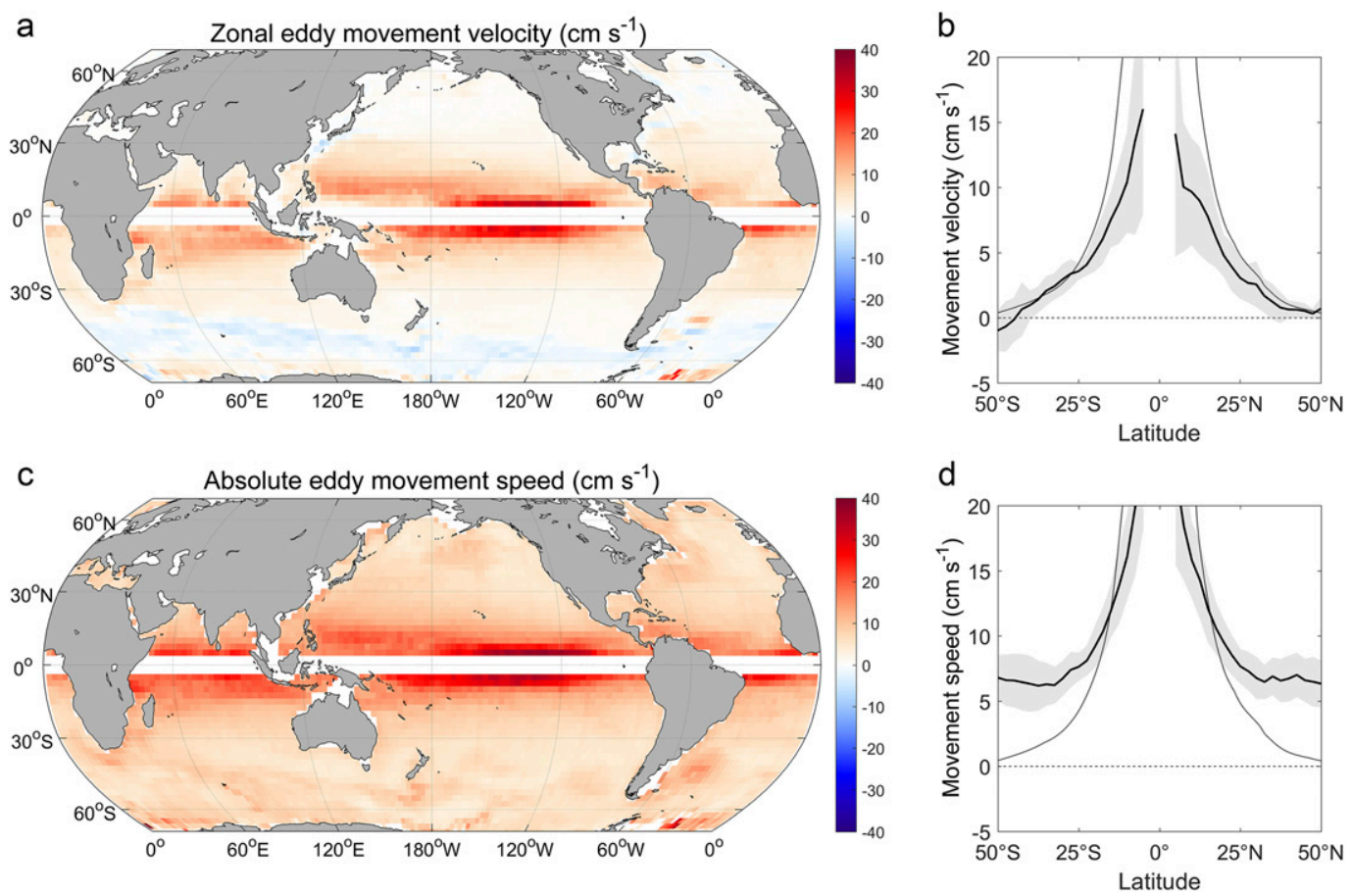

FIG. 3. Eddy movement speeds $\left(\mathrm{cm} \mathrm{s}^{-1}\right)$ calculated from the eddy trajectories. (a) Zonal eddy movement velocities averaged on a global $2.5^{\circ} \times 2.5^{\circ}$ grid. (b) Zonal mean (black bold curves) of (a) with one standard deviation (gray shadings). Black thin curves denote the phase speeds of linear Rossby waves (Chelton et al. 2011). (c),(d) As in (a) and (b), but for the absolute eddy movement speeds.

deflections of anticyclones (cyclones), which are typically on the order of $0.1 \mathrm{~cm} \mathrm{~s}^{-1}$ (Morrow et al. 2004).

\section{Eddy length scale}

In this section we analyze the length scales of detected mesoscale eddies and investigate eddy isotropy as well as its dependence on latitude. Rather than using the spectral method as in Eden (2007), here we directly make use of the identified eddy edges, i.e., outermost closed SLA contours, to estimate eddy length scales in the zonal and meridional directions. The zonal (meridional) length scale $R_{\text {zon }}\left(R_{\text {mer }}\right)$ of an eddy is defined as the average distance between the center of the eddy to the edges of the eddy in the zonal (meridional) direction.

Similar to previous results (Chelton et al. 2007, 2011), eddy length scales averaged over the 20-yr study period are found to depend strongly on latitude; both $R_{\text {zon }}$ and $R_{\text {mer }}$ decrease with latitude (Figs. 7a-d). On the other hand, although $R_{\text {zon }}$ and $R_{\text {mer }}$ are highly comparable at mid- and high latitudes, $R_{\text {zon }}$ is considerably larger than $R_{\text {mer }}$ at low latitudes $(\sim 200 \mathrm{~km}$ versus $\sim 150 \mathrm{~km}$ when zonally averaged). Our results thus confirm that mesoscale ocean eddies are indeed zonally elongated at low latitudes. At low latitudes, the turbulence and Rossby wave time scales overlap. As the time scale of the eddies increases through nonlinear interaction and becomes comparable to the time scale of Rossby waves, they are able to excite Rossby waves. As a result, turbulent eddy energy is transformed into Rossby waves or zonally elongated flow, i.e., the inverse energy cascade is arrested by $\beta$ (Rhines 1975). This is consistent with the fact that the eddies tracked from altimeter data are only weakly nonlinear at low latitudes (e.g., Chelton et al. 2011). Figure 8 shows the distribution of the nonlinearity parameter $U / c$ estimated using altimeter data, where $U$ is the maximum eddy rotational speed and $c$ is the eddy translation speed. Although the ratio of $U / c$ is almost everywhere larger than 1 (indicating nonlinear vortices), it is close to 1 (indicating more wavelike motions) in the tropical latitudes. Note that Fig. 8 only shows the surface estimates of $U / c$; we expect the values of $U / c$ at the subsurface to be smaller for baroclinic eddies whose rotational speeds decrease with depth.

To further quantify the degree of eddy anisotropy, we calculate the ratio between the zonal and meridional eddy length scales, i.e., $R_{\text {zon }} / R_{\text {mer }}$. As shown in Fig. 7 e, the anisotropy ratio exhibits considerable regional variability and has a value ranging from 0.9 to over 2 . This result is consistent with a previous estimate of eddy scales in a high-resolution model of the North Atlantic 

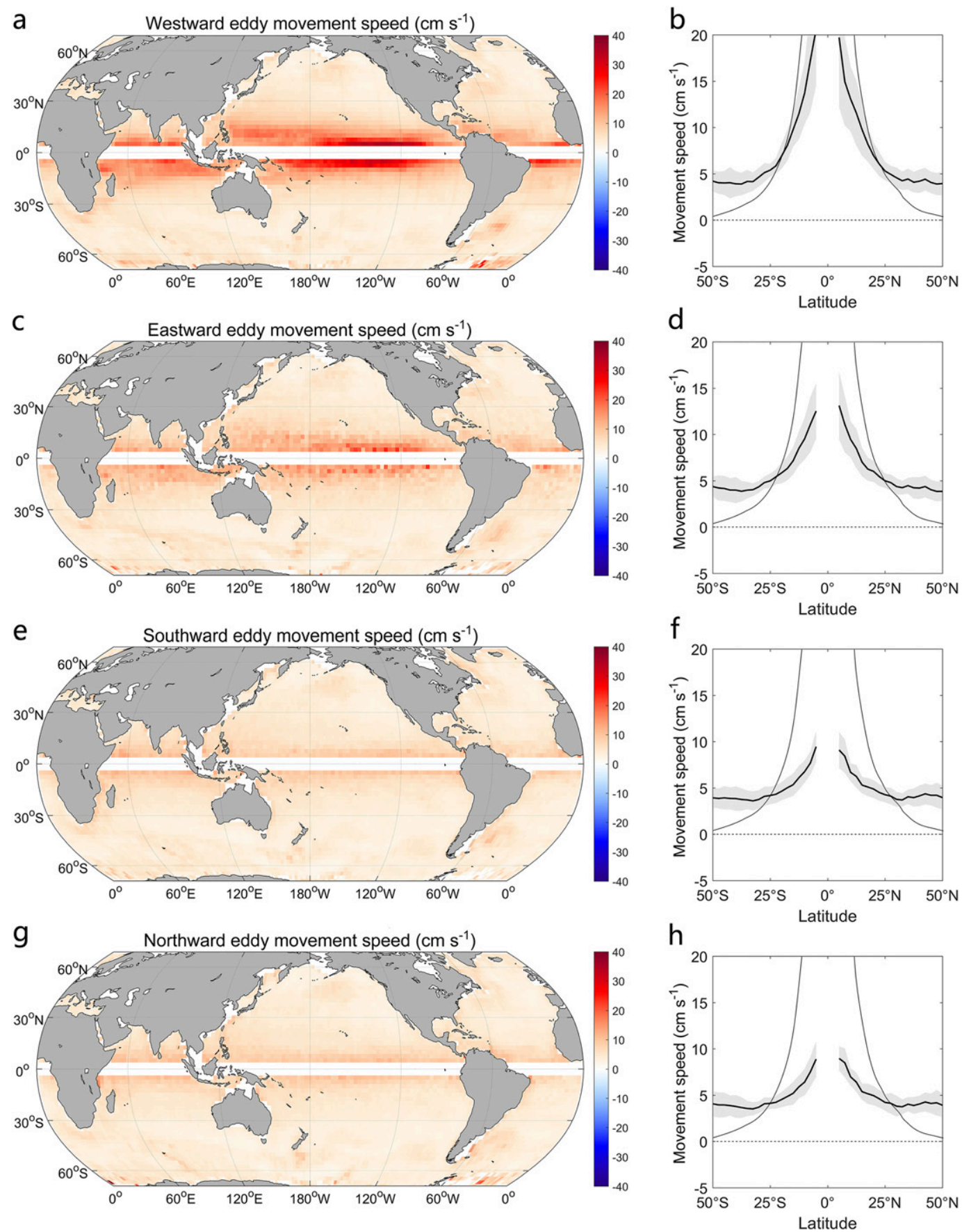

FIG. 4. Eddy movement speeds $\left(\mathrm{cm} \mathrm{s}^{-1}\right)$ in four directions on the global $2.5^{\circ} \times 2.5^{\circ}$ grid and their zonal averages (black bold curves) with one standard deviation (gray shadings). (a),(b) Westward component. (c),(d) Eastward component. (e),(f) Southward component. (g),(h) Northward component. Black thin curves in (b), (d), (f), and (h) denote the phase speeds of linear Rossby waves.

(Eden 2007), where the eddy zonal length scales were found to be $20 \%-100 \%$ larger than the meridional scales equatorward of $30^{\circ} \mathrm{N}$. When zonally averaged, the anisotropy ratio decreases from about 1.5 near the equator to close to 1 at mid- and high latitudes (Fig. 7f).
Interestingly, it is equatorward of $25^{\circ}$ latitude that the zonal eddy length scales become greater than the meridional ones. Therefore, both the tracked eddy movement speeds and estimated eddy length scales point to $\sim 25^{\circ}$ latitude as a critical latitude that separates the 

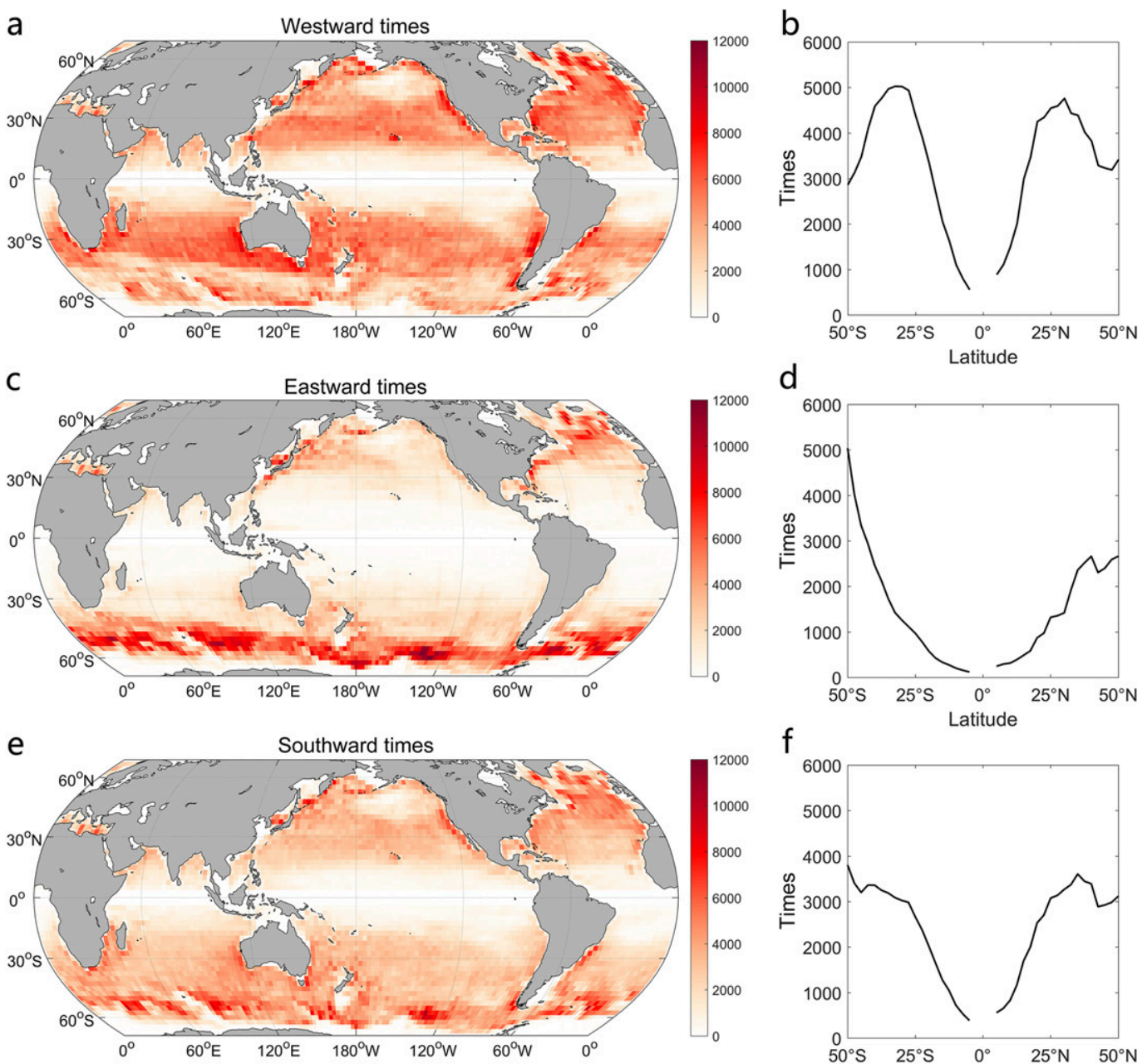

d

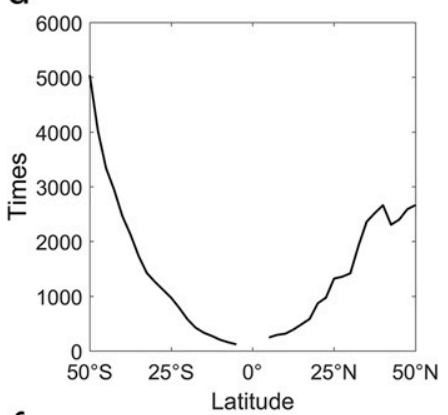

$\mathrm{f}$
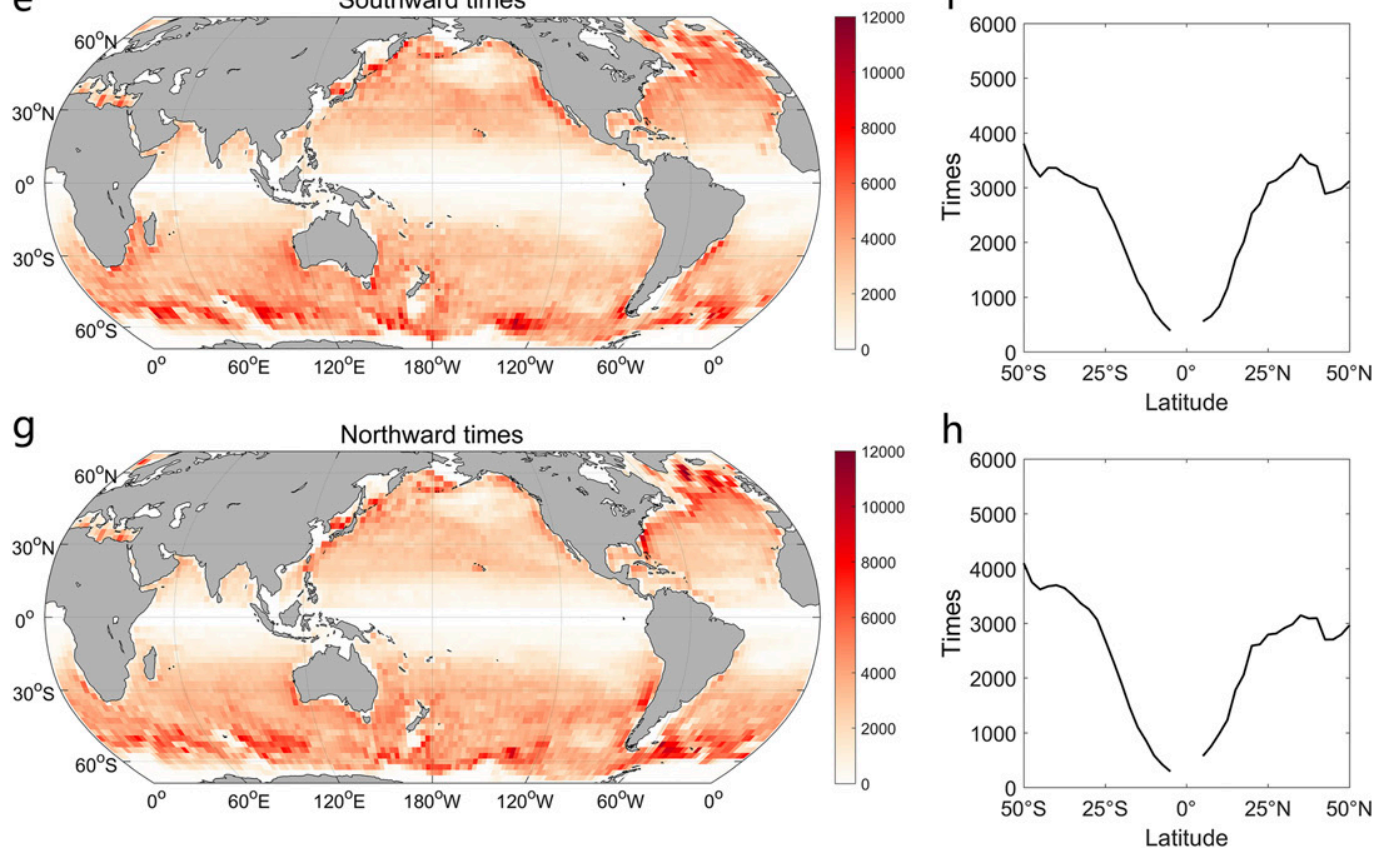

FIG. 5. (a)-(d) The number of times that eddies are detected to move in each of the four directions on the global $2.5^{\circ} \times 2.5^{\circ}$ grid and $(\mathrm{e})-(\mathrm{h})$ their zonal averages.

global ocean into a low-latitude anisotropic wavelike regime and a high-latitude isotropic turbulence regime.

\section{Eddy spreading experiment}

Two results on random eddy movement require further explanation: 1) Why do eddy random movement speeds decrease with latitude? 2) Why is the random eddy movement speed in the zonal direction noticeably larger than that in the meridional direction at low latitudes? To shed light on these questions, we carry out two sets of numerical experiments using a stochastically forced QG reduced-gravity model. The potential vorticity evolves through 
a

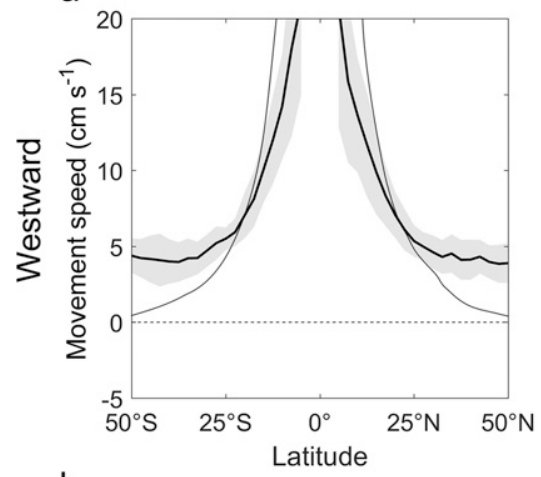

b

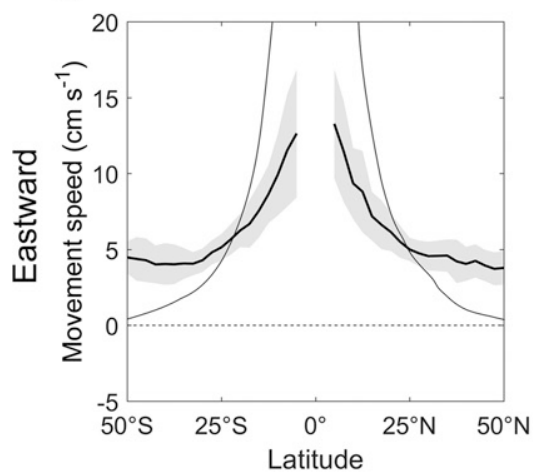

C

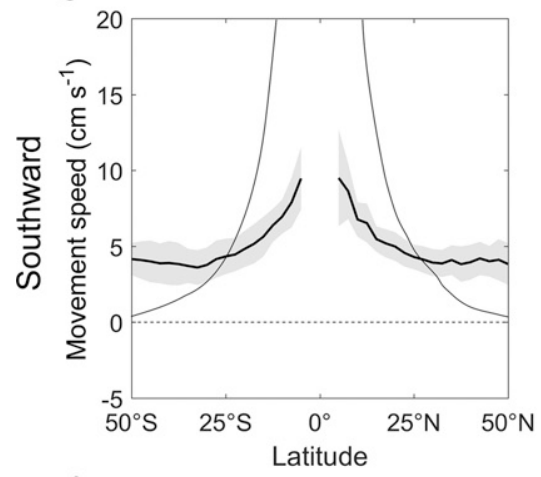

d

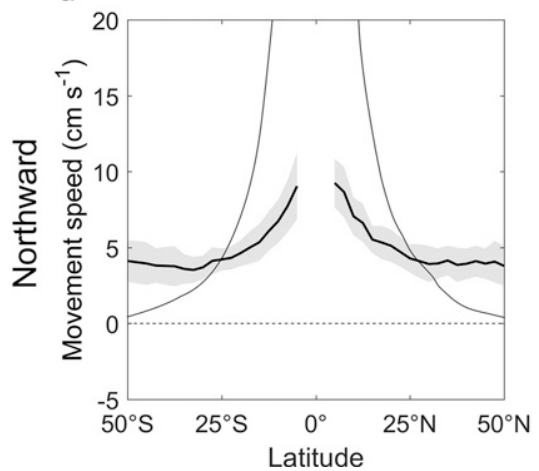

e

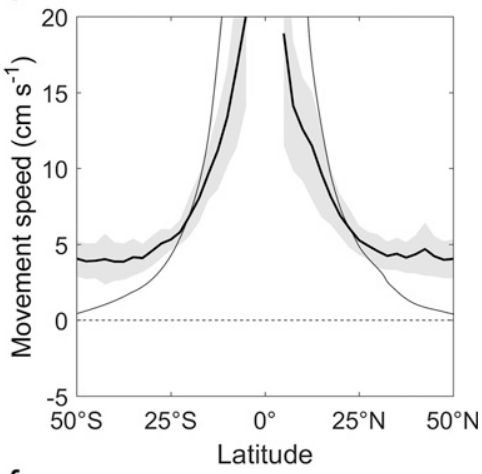

f

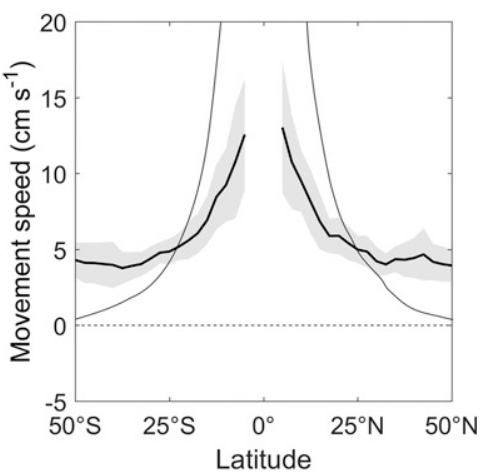

g

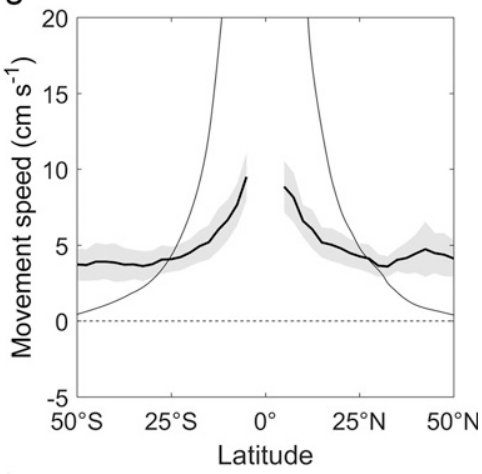

$\mathrm{h}$

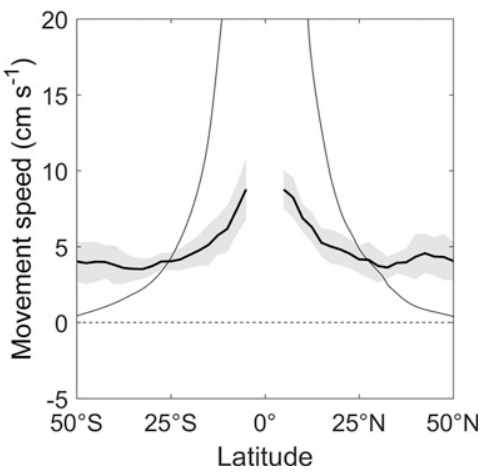

FIG. 6. (a)-(d) Eddy movement speeds (black bold curves) in four directions for anticyclonic eddies. Gray shadings show one standard deviation, and black thin curves denote the phase speeds of linear Rossby waves. (e)-(h) As in (a)-(d), but for cyclonic eddies. 

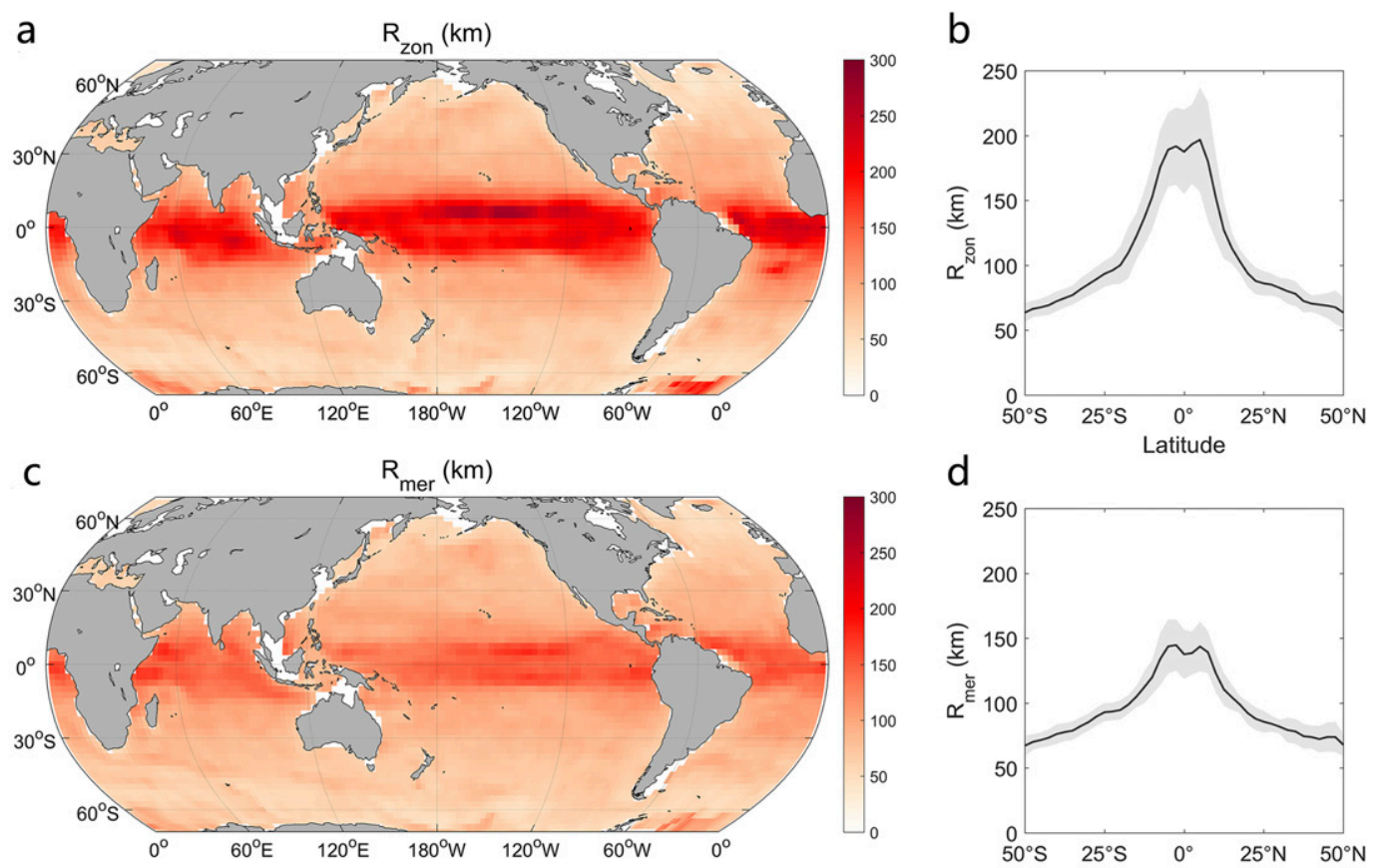

d
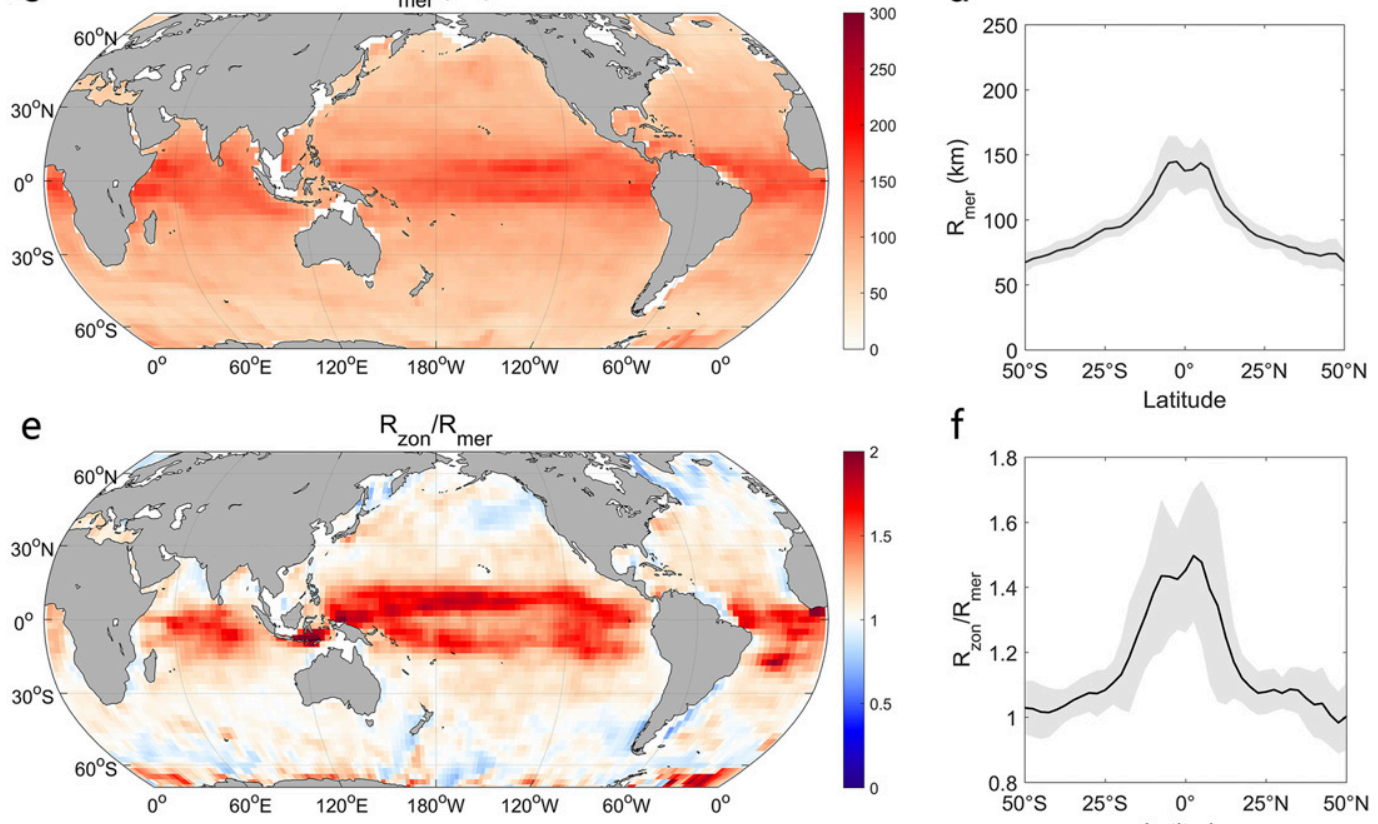

$f$

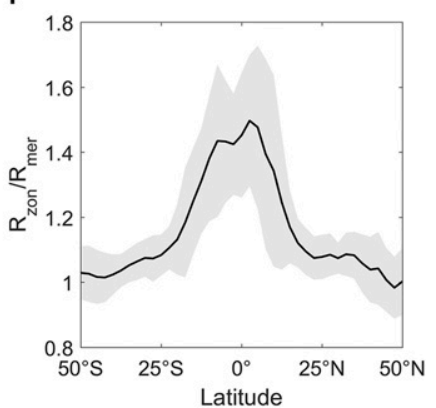

FIG. 7. (a) Estimated zonal eddy length scales $(\mathrm{km})$ on the global $2.5^{\circ} \times 2.5^{\circ}$ grid and (b) their zonal averages (black curves) with one standard deviation (gray shadings). (c),(d) As in (a) and (b), but for the meridional eddy length scales. (e),(f) As in (a) and (b), but for the ratio between the zonal and meridional eddy length scales.

$$
\begin{aligned}
\frac{\partial q}{\partial t}+J(\psi, q) & =\sigma F-\mu \nabla^{2} \psi+\nu_{2} \nabla^{4} \psi-\nu_{4} \nabla^{6} \psi, \\
q & =\nabla^{2} \psi-\frac{f^{2}}{g^{\prime} H} \psi+\beta y, \quad \text { and } \\
\psi & =\frac{g \eta}{f},
\end{aligned}
$$

where $q$ is the potential vorticity, $J$ is the Jacobian operator, $\psi$ is the streamfunction, $\sigma$ is the stochastic forcing amplitude, $F$ is the normalized stochastic forcing field, $\mu$ is the linear Ekman drag, $\nu_{2}$ is the Laplacian viscosity, $\nu_{4}$ is the hyperviscosity, $f$ is the Coriolis parameter, $g^{\prime}$ is the reduced gravity, $H$ is the thickness of the upper layer, $\beta$ is the meridional gradient of Coriolis parameter, $g$ is the gravitational acceleration, and $\eta$ is the SLA. To maintain a statistically steady eddy field, following
Samelson et al. (2016, 2019), $\sigma$ is obtained from $\sigma=$ $g f_{25} \sigma_{\eta} /\left(g^{\prime} H \Delta t\right.$ ) (where $\sigma_{\eta}$ is the amplitude of SLA increment, $f_{25}$ is the Coriolis parameter at $25^{\circ} \mathrm{N}$, and $\Delta t$ is the model time step), and $F$ is randomly generated at each time step in the same way as the initial eddy field (see below). Values of key model parameters are given in Table 1.

For all experiments, the domain is doubly periodic and the domain size is equal to $6400 \mathrm{~km}$ with a spatial resolution $(\Delta x, \Delta y)$ of $10 \mathrm{~km} \times 10 \mathrm{~km}$. The Fourier spectral method is used to calculate spatial derivatives and the fourth-order Runge-Kutta time stepping is used to integrate the model forward in time (Early et al. 2011; Constantinou 2018).

The initial eddy SLA field is synthesized via superposition of sinusoidal functions (e.g., Koszalka et al. 2009; Brannigan et al. 2015) 

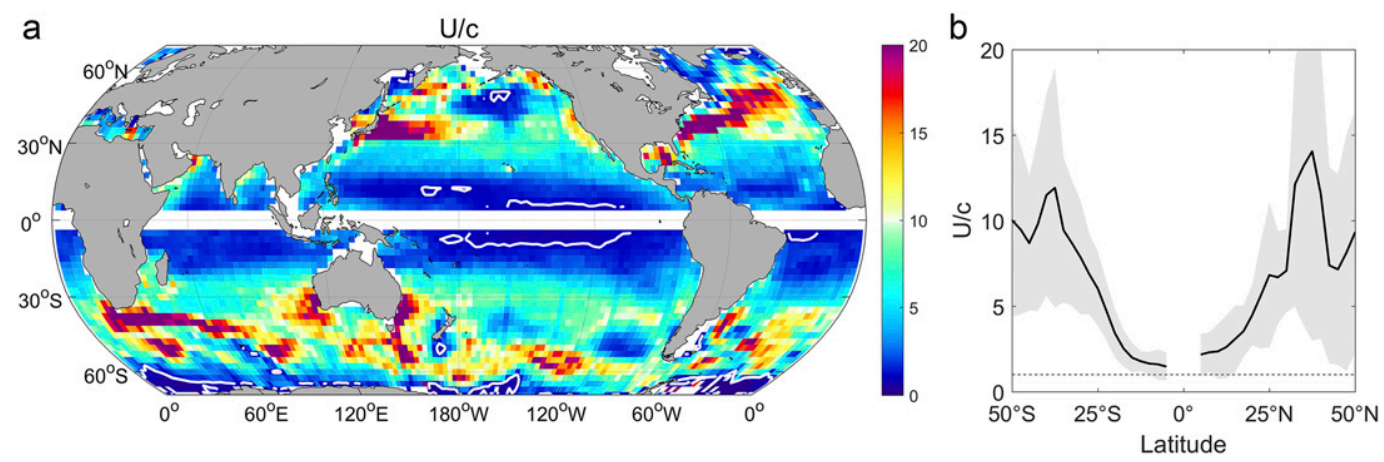

FIG. 8. (a) Nonlinearity parameter $U / c$ on the global $2.5^{\circ} \times 2.5^{\circ}$ grid estimated using all the eddy trajectories tracked over the 20 -yr period. White contours are contours of $U / c=1$. (b) Zonal average (black curves) of (a). Gray shadings indicate one standard deviation and dashed black line indicates $U / c=1$.

$$
\begin{aligned}
\eta= & \overline{\eta_{0}}\left[\sum_{k, l=1}^{20} \sin \left(\frac{2 \pi k x}{L}+\theta_{1}(k, l)\right)\right. \\
& \left.\times \sin \left(\frac{2 \pi l y}{L}+\theta_{2}(k, l)\right) \times G_{n}(\mathbf{k})\right]
\end{aligned}
$$

where $\overline{\eta_{0}}$ is the mean SLA at the center of eddies, $k$ and $l$ are the zonal and meridional components of wavenumber $\mathbf{k}, L$ is the domain size, $\theta_{i}$ is random phase angle, and square bracket denotes normalization by the magnitude. We use a Gaussian function $G_{n}(\mathbf{k})=\exp \left[-\left(|\mathbf{k}|-k_{0}\right)^{2} / 3.5^{2} / 2\right]$ in wavenumber space to confine eddy kinetic energy at around $|\mathbf{k}|=k_{0}$. To address the two questions set out in the beginning of this section, we carry out two sets of numerical experiments: one set on the $f$ plane (Experiment 1) and the other set on the $\beta$ plane (Experiment 2).

In Experiment 1, the QG model is run on the $f$ plane at different latitudes, increasing from $5^{\circ}$ to $50^{\circ} \mathrm{N}$ with an interval of $5^{\circ}$. The corresponding deformation radius ranges from $294 \mathrm{~km}$ at $5^{\circ} \mathrm{N}$ to $33 \mathrm{~km}$ at $50^{\circ} \mathrm{N}$. At each latitude, the model is run 20 times with different initial eddy fields randomly generated from (5). Only ensemblemean results are shown. In Eq. (5), we set $\overline{\eta_{0}}=15 \mathrm{~cm}$ and $k_{0}=10$ (i.e., with initial eddy radius of $\sim 160 \mathrm{~km}$ ) to ensure that the eddy time scale and Rossby wave time scale overlap at low latitudes (Theiss 2004; Fig. 9a). Furthermore, we scale initial $\eta$ in each model run by a factor of $f / f_{25}$ such that the magnitude of initial eddy velocity calculated through geostrophy is the same for all the model integrations centered at different latitudes. The purpose of Experiment 1 is to highlight the key factor behind the decrease of random eddy movement speeds with latitude.

In all the model runs in Experiment 1, eddy-eddy interaction leads to random eddy movement, regardless of whether they are centered at high or low latitudes. On the other hand, after applying the eddy detection and tracking procedure to the simulated eddy fields, we find that over the same time interval, eddy trajectories tracked at low latitudes (Fig. 9b) tend to be longer than those at high latitudes (Fig. 9c), indicating larger eddy movement speeds at lower latitudes. Ensemble averaging all the model simulations at each latitude shows that the simulated eddy movement speeds decrease with latitude (Fig. 10a), in a similar way as that diagnosed from altimeter data (Fig. 4). Given that the only key difference between model runs centered at different latitudes is the value of the Coriolis parameter, we conclude that it is the magnitude of $f$ that is the key factor behind the simulated decrease in random eddy movement speeds with latitude. In the QG reducedgravity model the eddy azimuthal velocity decays exponentially away from the eddy on a scale of the deformation radius (e.g., Larichev and McWilliams 1991). This can be seen by setting $\beta=0$ in (3) and then inverting a $q$ monopole to find $\psi$. Therefore, the primary effect of changing $f$ in model runs in Experiment 1 is to alter the deformation radius, which, in turn, alters the range of vortex interactions. At high latitudes where the deformation radius is smaller, the eddy azimuthal velocities decay exponentially away from the eddies at a faster rate and, as such, mutual advection of adjacent eddies is weaker and consequently smaller random eddy movement speeds at high latitudes.

The limitation with model runs in Experiment 1 is that in this experiment the eddy movement speeds are the same in all directions, i.e., isotropic (Fig. 10a), whereas in altimeter data the random eddy movement speed in the zonal direction is greater than that in the meridional direction at low latitudes. To explain the anisotropy in random eddy movement speeds at low latitudes, 


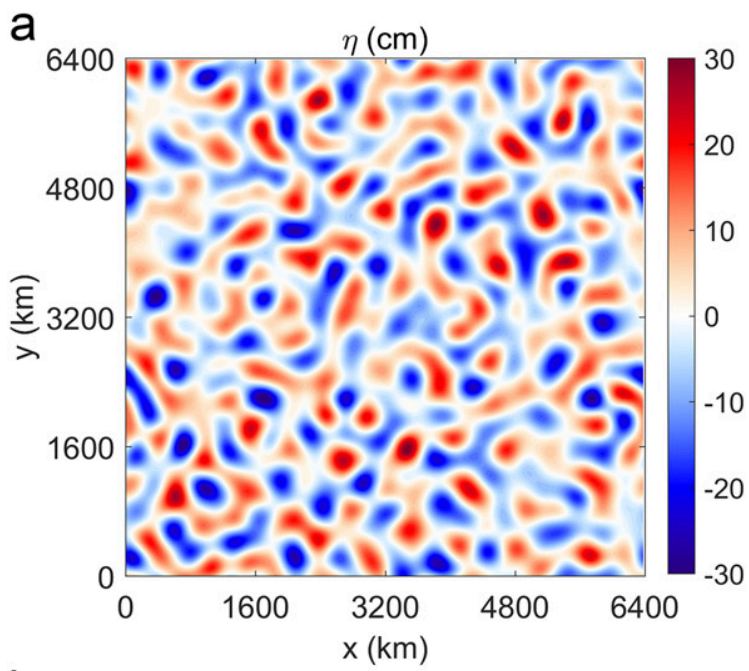

b
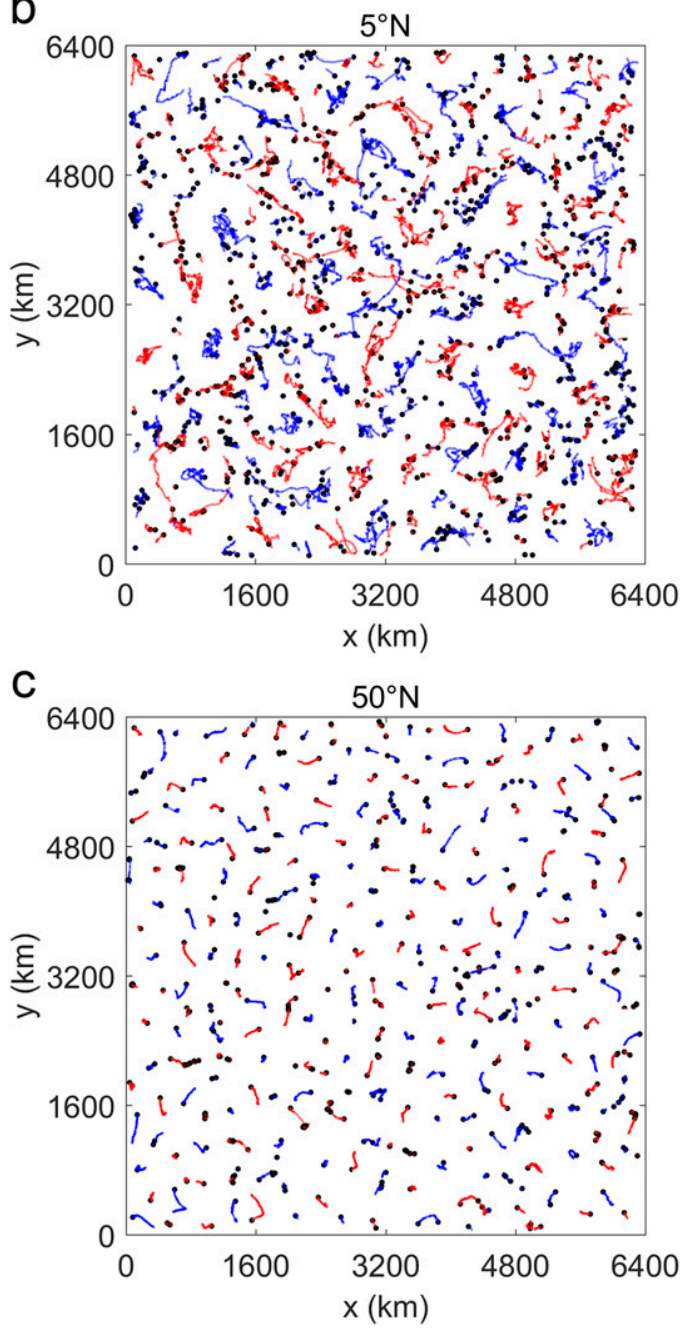

FIG. 9. (a) A random initial SLA field used in the stochastically forced quasigeostrophic (QG) reduced-gravity model. (b) Anticyclonic (red) and cyclonic (blue) eddy trajectories during the first 300 days of the model runs centered at $5^{\circ} \mathrm{N}$ in Experiment 1. Dots indicate the initial locations of these eddies. (c) As in (b), but for the model runs centered at $50^{\circ} \mathrm{N}$.
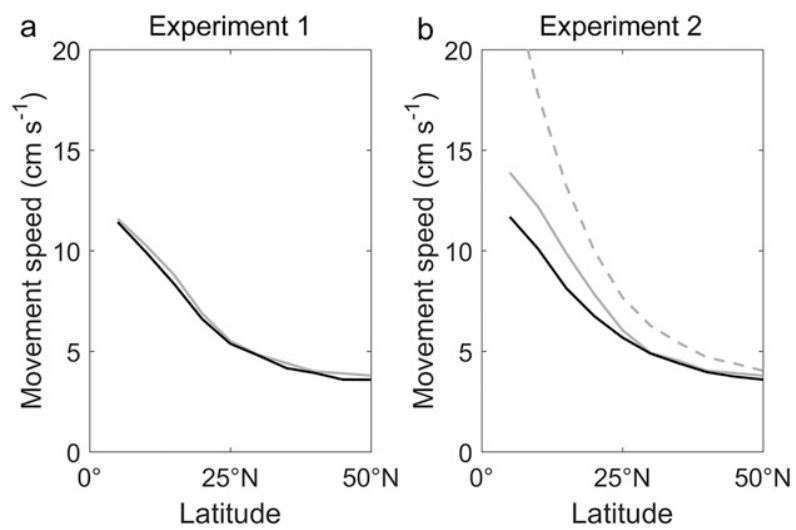

FIG. 10. Ensemble-mean eddy movement speeds estimated from QG Experiments 1 and 2. The black curves indicate the meridional eddy movement speeds, and solid (dashed) gray curves indicate the eastward (westward) eddy movement speeds.

we conduct another set of model integrations (Experiment 2 ), which are the same as those in Experiment 1 except on a $\beta$ plane. Figure $10 \mathrm{~b}$ shows that after introducing $\beta$, the ensemble-averaged eastward random movement speeds of the simulated eddies become noticeably larger than the meridional speeds at low latitudes, similar as that found in altimeter observations (Fig. 4). In addition to random movement, the eddies also propagate strongly westward. Furthermore, while the eddies in Experiment 2 remain isotropic in shape at high latitudes, they become zonally elongated at low latitudes due to the Rhines effect (Fig. 11; Rhines 1975). Results from Experiment 2 thus confirm that the difference between random eddy movement speeds in the zonal and meridional directions at low latitudes is due to $\beta$. Furthermore, it suggests a link between anisotropy in eddy zonal and meridional length scales and difference between zonal and meridional random eddy movement speeds, which we interpret as follows. When mesoscale eddies are zonally elongated, the zonal geostrophic currents on the meridional flanks of the eddies become swifter than the meridional currents on the zonal flanks, which results in stronger advection speeds in the zonal direction.

\section{Eddy energy diffusivity}

One consequence of random eddy movement is that it leads to lateral diffusion of eddy energy, but the associated eddy energy diffusivity is yet to be determined. A widely used method for estimating lateral eddy diffusivity in the ocean is through statistical analyses of Lagrangian drifter and float trajectories (e.g., Davis 1991; LaCasce 2008a; Roach et al. 2016, 2018), particularly in the meridional direction where drifter/float 
TABLE 1. Parameters used in the stochastically forced QG reduced-gravity model.

\begin{tabular}{lcc}
\hline \multicolumn{1}{c}{ Parameter } & Symbol & Value \\
\hline Amplitude of SLA increment & $\sigma_{\eta}$ & $0.01 \mathrm{~m}$ \\
Ekman drag coefficient & $\mu$ & $2.5 \times 10^{-7} \mathrm{~s}^{-1}$ \\
Laplacian viscosity coefficient & $\nu_{2}$ & $25 \mathrm{~m}^{2} \mathrm{~s}^{-1}$ \\
Hyperviscosity coefficient & $\nu_{4}$ & $2 \times 10^{9} \mathrm{~m}^{4} \mathrm{~s}^{-1}$ \\
Coriolis parameter & $f$ & Depends on latitude \\
Meridional gradient of Coriolis & $\beta$ & Depends on latitude \\
$\quad$ parameter & & \\
Reduced gravity & $g^{\prime}$ & $0.02 \mathrm{~m} \mathrm{~s}^{-2}$ \\
Thickness of the upper layer & $H$ & $700 \mathrm{~m}$ \\
Gravitational acceleration & $g$ & $9.81 \mathrm{~m} \mathrm{~s}^{-2}$ \\
Domain size & $L$ & $6400 \mathrm{~km}$ \\
Time step & $\Delta t$ & $3600 \mathrm{~s}$ \\
Spatial resolution & $\Delta x, \Delta y$ & $10 \mathrm{~km}$ \\
\hline
\end{tabular}

movement is less influenced by the Rossby waves and mean flow (LaCasce et al. 2014; Klocker and Abernathey 2014). Inspired by these earlier drifter/float-based studies, we estimate eddy energy diffusivity associated with random eddy movement using the tracked eddy trajectories from altimeter data. Recall that the majority of the mesoscale features we identified and tracked from altimeter data are nonlinear eddies, rather than linear wave disturbances, as measured by the nonlinearity parameter U/c (Fig. 8). Two different methods (LaCasce 2008a; LaCasce et al. 2014; Roach et al. 2018) are used here:

1) Single-particle separation (three versions):

$$
\begin{aligned}
K_{1}(t) & =\left\langle v(t)\left[y(t)-y_{0}\right]\right\rangle, \\
K_{2}(t) & =\frac{1}{2} \frac{d}{d t}\left\langle\left[y(t)-y_{0}\right]^{2}\right\rangle, \\
K_{3}(t) & =\frac{\left\langle\left[y(t)-y_{0}\right]^{2}\right\rangle}{2 t},
\end{aligned}
$$

where $K$ is the meridional diffusivity, $v(t)$ is the meridional eddy movement velocity as a function of time, $y(t)$ is the meridional location of a detected eddy and $y_{0}$ is the initial location of the eddy. The angle bracket denotes averaging of all the eddies with trajectories originating inside $5^{\circ} \times 5^{\circ}$ bins centered at grid points of the global $2.5^{\circ} \times 2.5^{\circ}$ grid (see appendix B; Fig. B1). Should there be less than 25 tracked eddies within any $5^{\circ} \times 5^{\circ}$ bin over the 20 yr period, no calculation of $K$ is attempted in that bin.

2) Two-particle separation:

$$
K_{4}(t)=\frac{\left|\left\langle D(t)^{2}\right\rangle-\left\langle D_{0}^{2}\right\rangle\right|}{4 t}
$$

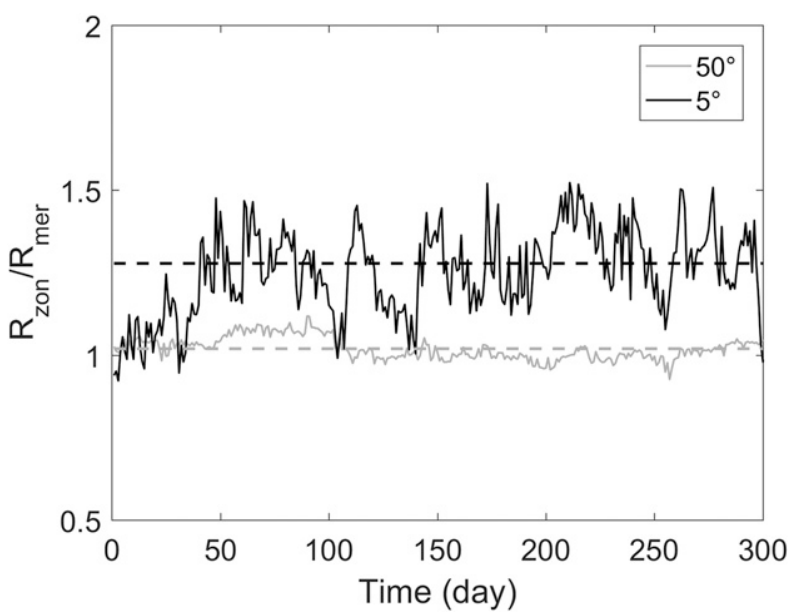

FIG. 11. Domain-averaged ratios between the zonal and meridional eddy length scales from QG Experiment 2 model runs centered at $5^{\circ} \mathrm{N}$ (black) and $50^{\circ} \mathrm{N}$ (gray), respectively. The dashed lines denote time averages.

where $D(t)$ is the meridional distance between two centers of paired eddies, $D_{0}$ is the initial distance between them and the modulus operator means taking the absolute value. To ensure sufficient samples, two eddies of the same polarity in the same bin but at different times are also regarded as a pair, assuming that changes of eddy diffusivity over the 20-yr study period are not significant (Roach et al. 2018).

The overall magnitude and spatial pattern of eddy energy diffusivities estimated from single-particle and twoparticle separations are similar away from the western boundaries (Figs. 12a-d). Near the western boundaries, the magnitudes of $K_{1}-K_{3}$ become significantly elevated with several pronounced hot spots but these are absent in $K_{4}$. This difference can be explained by advection of eddies by the background western boundary currents which strongly enhances eddy diffusivity estimated from single-particle separation but has less effect on eddy diffusivity estimated from two-particle separation. The zonal-mean values of all four diffusivities are found to decrease with latitude, from over $1500 \mathrm{~m}^{2} \mathrm{~s}^{-1}$ close to the equator to about $500 \mathrm{~m}^{2} \mathrm{~s}^{-1}$ at high latitudes, but significantly larger values are found in the eddy energy hotspots at all latitudes, in excess of $5000 \mathrm{~m}^{2} \mathrm{~s}^{-1}$ (Fig. 12e). These numbers are generally comparable to previous estimates of eddy tracer diffusivities based on Eulerian and/or Lagrangian methods (e.g., Abernathey and Marshall 2013; LaCasce et al. 2014; Klocker and Abernathey 2014).

Note that eddy energy transport/diffusion is fundamentally different from eddy tracer transport/diffusion. There is a debate on the importance of eddy "drift" tracer transport, that is, tracer transport achieved by 

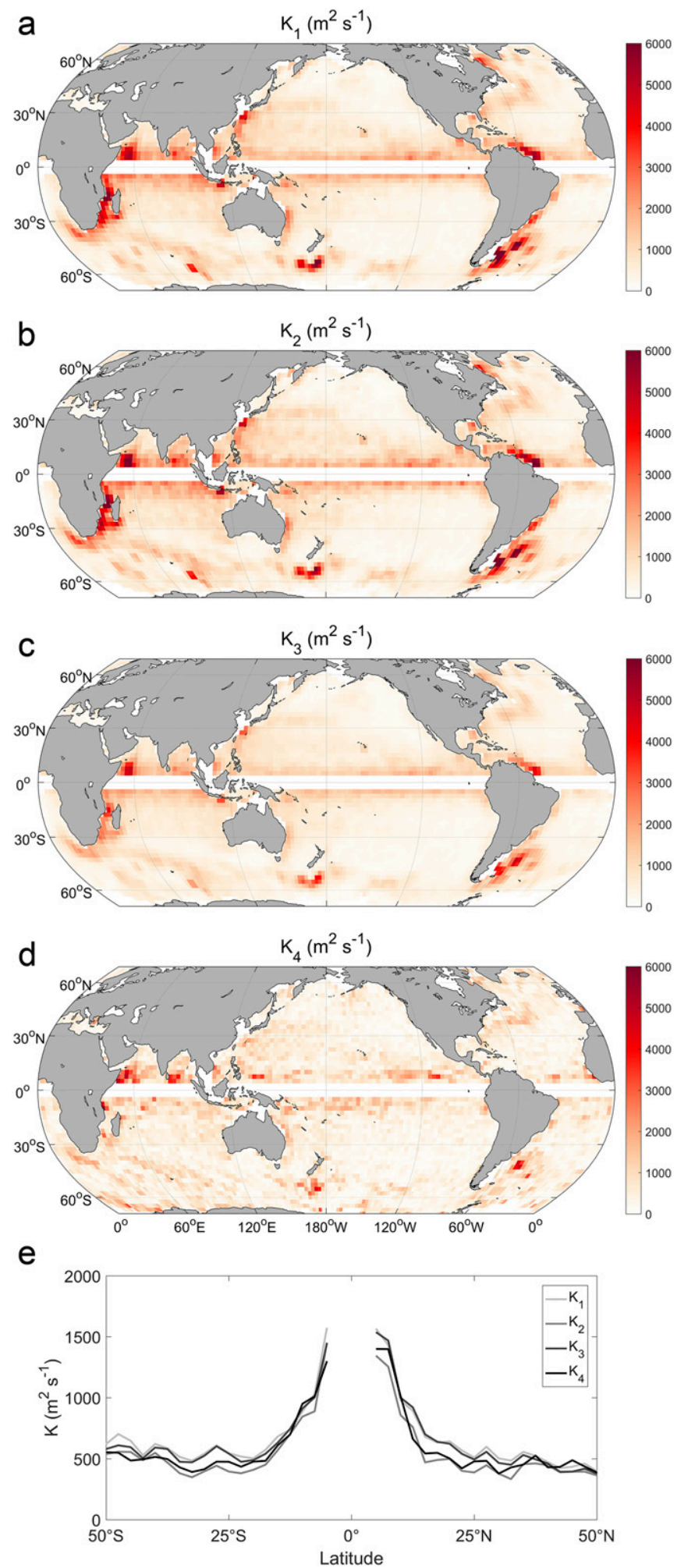

FIG. 12. (a)-(d) Global distributions of eddy energy diffusivities $K_{1}-K_{4}\left(\mathrm{~m}^{2} \mathrm{~s}^{-1}\right)$ estimated from eddy trajectories based on different algorithms and (e) their zonal means. 


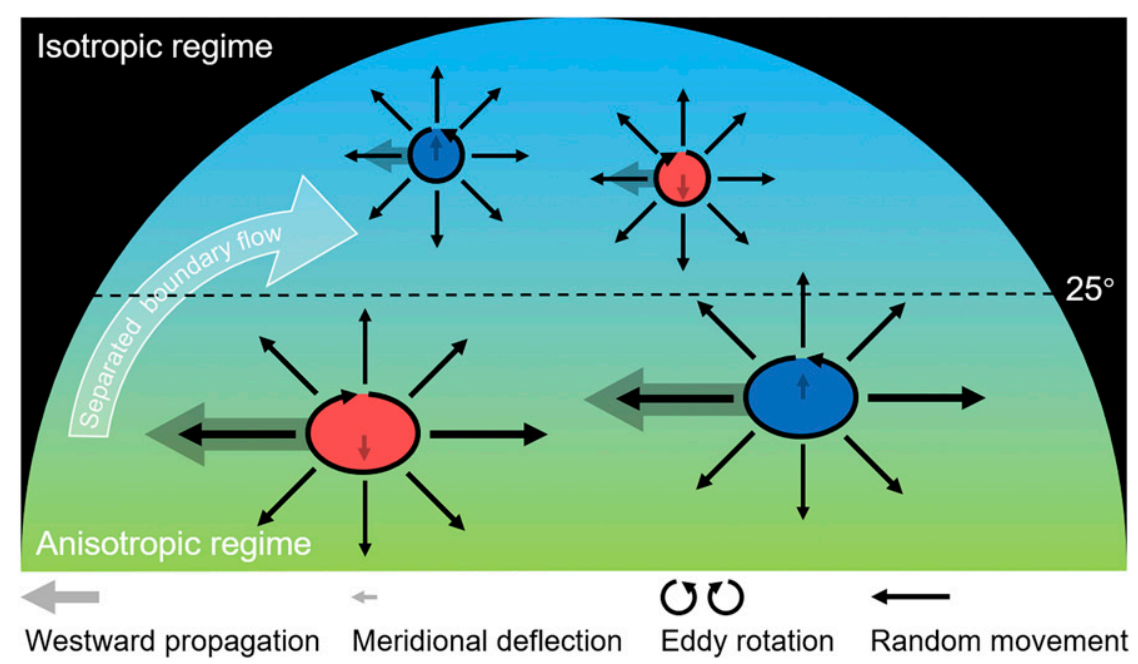

FIG. 13. Schematic of eddy movement in the global ocean, taking the Northern Hemisphere as an example.

eddies through trapping and translating tracer anomalies (e.g., Beron-Vera et al. 2013; Abernathey and Haller 2018). At the center of this debate is the unknown ability of eddies to trap and translate fluid. However, this eddy tracer trapping efficiency has no bearing on eddy energy diffusivity diagnosed in our study from random eddy movement, since eddy energy is a property of the eddies. Moreover, this eddy energy diffusivity is a fundamental ingredient for recent eddy parameterizations that involve solving a prognostic eddy energy equation (e.g., Eden and Greatbatch 2008; Marshall and Adcroft 2010; Marshall et al. 2012; Jansen and Held 2014; Jansen et al. 015; Mak et al. 2018).

\section{Conclusions}

In this study we have tracked and analyzed eddy trajectories in the global ocean using 20 years of satellite altimeter data, and shown that, in addition to the wellknown westward propagation and slight polarity-based meridional deflections, mesoscale eddies move randomly at all latitudes. The random eddy movement speeds have been found to decrease with latitude and equal the Rossby wave speed at about $25^{\circ}$ latitude. Furthermore, the random eddy movement speeds were found to be isotropic at mid- and high latitudes but larger in the zonal direction than meridional direction at low latitudes. We also estimated eddy length scales using the identified eddy edges and found that mesoscale eddies are on average isotropic in shape at mid- and high latitudes but become increasingly zonally elongated equatorward of $\sim 25^{\circ}$ latitude. Therefore, both the tracked eddy movement speeds and identified eddy length scales suggest a critical latitude of approximately $25^{\circ}$ that separates the global ocean into a low-latitude anisotropic wavelike regime and a high-latitude isotropic turbulence regime (Theiss 2004; Eden 2007; Tulloch et al. 2009; Fig. 13).

We then conducted two sets of stochastically forced QG reduced-gravity model experiments to investigate the key factors behind two notable features in the diagnosed random eddy movement, i.e., decreasing speed with latitude and anisotropy at low latitudes. In the first set of model experiments, the QG model was run on the $f$ plane at a wide range of discrete latitudes and the results demonstrate that it is the increase in the magnitude of the Coriolis parameter with latitude that results in the decrease in random eddy movement speeds with latitude. A large $f$ value at high latitudes mean a smaller deformation radius and hence a smaller range of vortex interactions, since the eddy azimuthal velocity decays exponentially away from the eddy on a scale of the deformation radius (e.g., Larichev and McWilliams 1991). In the second set of model experiments, we ran the QG model on the $\beta$ plane and the results strongly suggest that it is the anisotropy in eddy zonal and meridional length scales that leads to the difference between random eddy movement speeds in the zonal and meridional directions at low latitudes. When eddies are zonally elongated, their pressure gradient in the meridional direction becomes greater than that in the zonal direction which, via geostrophy, results in stronger zonal currents on the meridional flanks of the eddies.

One important consequence of random eddy movement is that it results in lateral diffusion of eddy energy. 
a

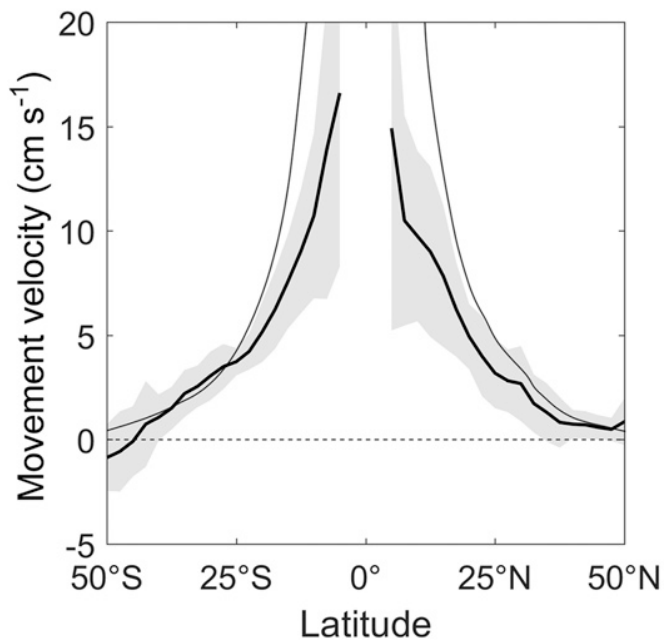

b

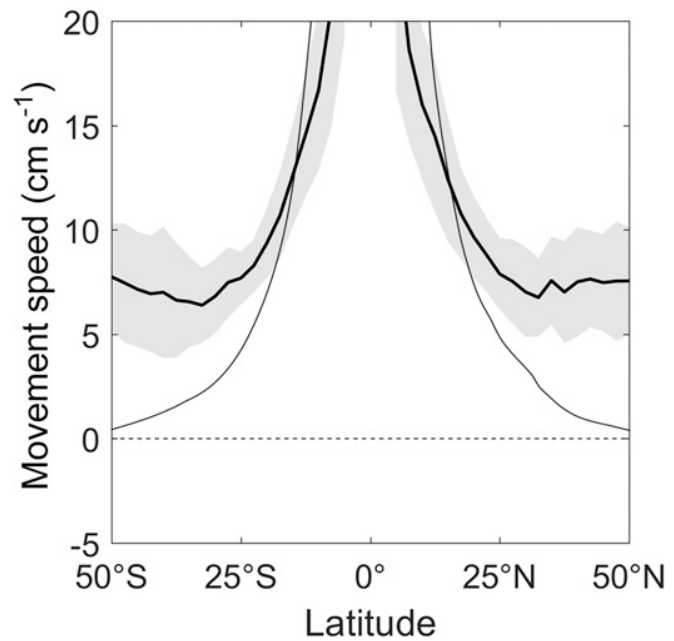

FIG. A1. (a) Zonal eddy movement velocities and (b) absolute eddy movement speeds calculated from an alternative eddy tracking method via finding the closest centroid of the eddy edge (Chelton et al. 2011).

The eddy energy diffusivity associated with random eddy movement has been estimated by applying singleparticle and two-particle separation methods to the tracked eddy trajectories from altimeter data. The zonalmean eddy diffusivities estimated from both methods were found to be a function of latitude, decreasing from over $1500 \mathrm{~m}^{2} \mathrm{~s}^{-1}$ close to the equator to about $500 \mathrm{~m}^{2} \mathrm{~s}^{-1}$ at high latitudes, with larger values in eddy energy hotspots in excess of $5000 \mathrm{~m}^{2} \mathrm{~s}^{-1}$. This estimated eddy energy diffusivity is of direct benefit to recently proposed energetically consistent mesoscale eddy parameterization schemes which require solving an explicit eddy energy budget to control the magnitude of eddy transfer coefficients (Eden and Greatbatch 2008; Marshall and Adcroft 2010; Marshall et al. 2012; Jansen and Held 2014), since one of the unknowns in this eddy energy budget is the lateral eddy energy diffusion coefficient.

Acknowledgments. Q. Ni acknowledges support by a visiting scholarship from the Chinese Scholarship Council and NSFC Grant 41811530301. X. Zhai is supported by a Royal Society International Exchanges Award (IEC/NSFC/170007). X. Zhai and D. Marshall acknowledge partial support from the U.K. Natural Environment Research Council, NE/R000999/1. G. Wang acknowledges support by Grant 17XD1400600, 2017YFC1404103 and NSFC Grants 41576022, 41976003. Q. Ni thanks Xuemin Jiang, Chuanyin Wang, Zhibin Yang, and Shenjie Zhou for helpful discussions. We thank Jonas Nycander, Joe LaCasce, and two anonymous reviewers for their constructive comments that led to significant improvement of this manuscript.

\section{APPENDIX A}

\section{Robustness of the Diagnosed Random Eddy Movement}

To assess the robustness of the random movement of mesoscale eddies in the global ocean, we utilize an alternative eddy tracking method (Chelton et al. 2011). This method is performed by tracking the closest centroid of the outermost closed SLA contour within the search circle. The resulting eddy movement speeds (Fig. A1) are

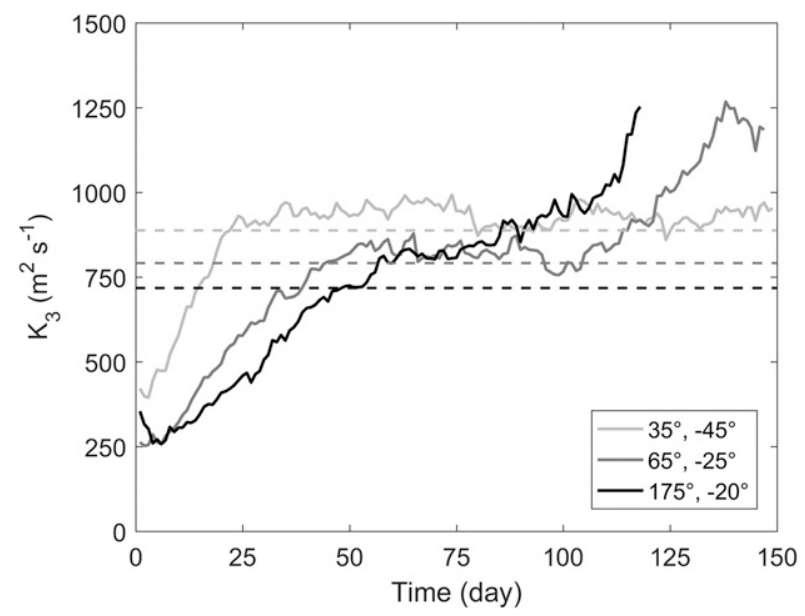

FIG. B1. Eddy energy diffusivities in different regions (solid curves) as a function of time together with their time averages over the lifetime of detected eddies (dashed lines). The diffusivities estimated within the $5^{\circ} \times 5^{\circ}$ bins centered at $\left(35^{\circ},-45^{\circ}\right),\left(65^{\circ}\right.$, $\left.-25^{\circ}\right)$, and $\left(175^{\circ},-20^{\circ}\right)$ are shown in light gray, dark gray, and black, respectively. 
very similar to those as described previously (Figs. 3b,d). In addition, the limited $1 / 4^{\circ}$ spatial resolution of the gridded altimetry data may miss some SLA extrema. Thus, we apply the daily $1 / 12^{\circ}$ HYCOM SLA output (https://hycom.org/) to estimate the associated errors. First, the daily HYCOM SLA maps are processed via a bandpass Gaussian filter with half-power cutoff wavelengths between $1^{\circ}$ and $10^{\circ}$ to isolate mesoscale signals. Then, the filtered SLA maps are subsampled from the original $0.08^{\circ} \times 0.08^{\circ}$ grid to a coarser grid of $0.25^{\circ} \times$ $0.25^{\circ}$. Finally, mesoscale eddies are identified and tracked on the original and coarser grids, respectively. Comparing the results of the two grids, it is found that subsampling to the coarser grid has only induced a $6.3 \%$ overestimate of the eddy movement speeds over the World Ocean. Therefore, the random eddy movement presented in this study is believed to be robust.

\section{APPENDIX B}

\section{Estimation of Representative Eddy Energy Diffusivity}

Previous drifter/float-based studies typically define the local representative eddy diffusivity by averaging the asymptotic diffusivity over a short period, i.e., tens of days (e.g., LaCasce et al. 2014; Roach et al. 2016, 2018). As shown in Fig. B1, while the eddy energy diffusivity in some regions tends to level off after about 25-50 days (solid gray curves), the eddy energy diffusivity in other regions keeps increasing with time (solid black curve), a superdiffusive regime that LaCasce (2008b) attributes to the vortices being an active rather than passive tracer. In this study, eddy energy diffusivity in each bin is defined as the average eddy energy diffusivity over the lifetime of detected eddies in that bin (dashed lines).

\section{REFERENCES}

Abernathey, R., and G. Haller, 2018: Transport by Lagrangian vortices in the eastern Pacific. J. Phys. Oceanogr., 48, 667-685, https://doi.org/10.1175/JPO-D-17-0102.1.

Abernathey, R. P., and J. Marshall, 2013: Global surface eddy diffusivities derived from satellite altimetry. J. Geophys. Res. Oceans, 118, 901-916, https://doi.org/10.1002/jgrc.20066.

Beron-Vera, F. J., Y. Wang, M. J. Olascoaga, G. Goni, and G. Haller, 2013: Objective detection of oceanic eddies and the Agulhas leakage. J. Phys. Oceanogr., 43, 1426-1438, https:// doi.org/10.1175/JPO-D-12-0171.1.

Brannigan, L., D. P. Marshall, A. Naveira-Garabato, and A. J. George Nurser, 2015: The seasonal cycle of submesoscale flows. Ocean Modell., 92, 69-84, https://doi.org/10.1016/j.ocemod.2015.05.002.

Chaigneau, A., M. L. Texier, G. Eldin, C. Grados, and O. Pizarro, 2011: Vertical structure of mesoscale eddies in the eastern south Pacific ocean: A composite analysis from altimetry and
Argo profiling floats. J. Geophys. Res., 116, C11025, https:// doi.org/10.1029/2011JC007134.

Chassignet, E. P., and B. Cushman-Roisin, 1991: On the influence of a lower layer on the propagation of nonlinear oceanic eddies. J. Phys. Oceanogr., 21, 939-957, https://doi.org/10.1175/ 1520-0485(1991)021<0939:OTIOAL > 2.0.CO;2.

Chelton, D. B., M. G. Schlax, R. M. Samelson, and R. A. De Szoeke, 2007: Global observations of large oceanic eddies. Geophys. Res. Lett., 34, L15606, https://doi.org/10.1029/2007GL030812.

,-- , and -2011 : Global observations of nonlinear mesoscale eddies. Prog. Oceanogr., 91, 167-216, https://doi.org/ 10.1016/j.pocean.2011.01.002.

Constantinou, N. C., 2018: A barotropic model of eddy saturation. J. Phys. Oceanogr., 48, 397-411, https://doi.org/10.1175/ JPO-D-17-0182.1.

Conway, T. M., J. B. Palter, and G. F. de Souza, 2018: Gulf Stream rings as a source of iron to the North Atlantic subtropical gyre. Nat. Geosci., 11, 594-598, https://doi.org/10.1038/s41561-018-0162-0.

Cushman-Roisin, B., B. Tang, and E. Chassignet, 1990: Westward motion of mesoscale eddies. J. Phys. Oceanogr., 20, 758-768, https://doi.org/10.1175/1520-0485(1990)020<0758:WMOME $>$ 2.0.CO;2.

Davis, R., 1991: Observing the general circulation with floats. Deep-Sea Res., 38A, S531-S571, https://doi.org/10.1016/ S0198-0149(12)80023-9.

Dong, C., J. C. Mcwilliams, Y. Liu, and D. Chen, 2014: Global heat and salt transports by eddy movement. Nat. Commun., 5, 3294, https://doi.org/10.1038/ncomms4294.

Early, J. J., R. M. Samelson, and D. B. Chelton, 2011: The evolution and propagation of quasigeostrophic ocean eddies. J. Phys. Oceanogr., 41, 1535-1555, https://doi.org/10.1175/2011JPO4601.1.

Eden, C., 2007: Eddy length scales in the North Atlantic Ocean. J. Geophys. Res., 112, C06004, https://doi.org/10.1029/ 2006JC003901.

— sure. Ocean Modell., 20, 223-239, https://doi.org/10.1016/ j.ocemod.2007.09.002.

Ferrari, R., and C. Wunsch, 2010: The distribution of eddy kinetic and potential energies in the global ocean. Tellus, $62 \mathbf{A}, 92-108$, https://doi.org/10.3402/tellusa.v62i2.15680.

Grooms, I., 2015: A computational study of turbulent kinetic energy transport in barotropic turbulence on the f-plane. Phys. Fluids, 27, 101701, https://doi.org/10.1063/1.4934623.

_ 2017: Simulations of eddy kinetic energy transport in barotropic turbulence. Phys. Rev. Fluids, 2, 113801, https://doi.org/ 10.1103/PhysRevFluids.2.113801.

Hughes, C. W., and P. I. Miller, 2017: Rapid water transport by long-lasting modon eddy pairs in the southern midlatitude oceans. Geophys. Res. Lett., 44, 12 375-12 384, https://doi.org/ 10.1002/2017GL075198

Jansen, M. F., and I. M. Held, 2014: Parameterizing subgrid-scale eddy effects using energetically consistent backscatter. Ocean Modell., 80, 36-48, https://doi.org/10.1016/j.ocemod.2014.06.002.

—_, A. J. Adcroft, R. Hallberg, and I. M. Held, 2015: Parameterization of eddy fluxes based on a mesoscale energy budget. Ocean Modell., 92, 28-41, https://doi.org/ 10.1016/j.ocemod.2015.05.007.

Klocker, A., and R. Abernathey, 2014: Global patterns of mesoscale eddy properties and diffusivities. J. Phys. Oceanogr., 44, 1030-1046, https://doi.org/10.1175/JPO-D-13-0159.1.

_ , and D. P. Marshall, 2014: Advection of baroclinic eddies by depth mean flow. Geophys. Res. Lett., 41, 3517-3521, https:// doi.org/10.1002/2014GL060001. 
S. R. Keating, and P. L. Read, 2016: A regime diagram for ocean geostrophic turbulence. Quart. J. Roy. Meteor. Soc., 142, 2411-2417, https://doi.org/10.1002/qj.2833.

Koszalka, I. M., A. Bracco, J. C. Mcwilliams, and A. Provenzale, 2009: Dynamics of wind-forced coherent anticyclones in the open ocean. J. Geophys. Res., 114, C08011, https://doi.org/ 10.1029/2009JC005388.

LaCasce, J. H., 2008a: Statistics from Lagrangian observations. Prog. Oceanogr., 77 (1), 1-29, https://doi.org/10.1016/j.pocean. 2008.02.002.

- 2008b: The vortex merger rate in freely decaying twodimensional turbulence. Phys. Fluids, 20, 085102, https:// doi.org/10.1063/1.2957020.

_- , R. Ferrari, R. Tulloch, D. Balwada, and K. G. Speer, 2014: Float-derived isopycnal diffusivities in the DIMES Experiment. J. Phys. Oceanogr., 44, 764-780, https://doi.org/ 10.1175/JPO-D-13-0175.1.

Larichev, V. D., and J. C. Mcwilliams, 1991: Weakly decaying turbulence in an equivalent-barotropic fluid. Phys. Fluids, $\mathbf{3}$, 938-950, https://doi.org/10.1063/1.857970.

Mak, J., J. R. Maddison, D. P. Marshall, and D. R. Munday, 2018: Implementation of a geometrically informed and energetically constrained mesoscale eddy parameterization in an ocean circulation model. J. Phys. Oceanogr., 48, 2363-2382, https:// doi.org/10.1175/JPO-D-18-0017.1.

Marshall, D. P., and A. Adcroft, 2010: Parameterization of ocean eddies: Potential vorticity mixing, energetics and Arnold's first stability theorem. Ocean Modell., 32, 188-204, https://doi.org/ 10.1016/j.ocemod.2010.02.001.

_ _ J. R. Maddison, and P. S. Berloff, 2012: A framework for parameterizing eddy potential vorticity fluxes. J. Phys. Oceanogr., 42, 539-557, https://doi.org/10.1175/JPO-D-11-048.1.

McWilliams, J., and G. Flierl, 1979: On the evolution of isolated, nonlinear vortices. J. Phys. Oceanogr., 9, 1155-1182, https:// doi.org/10.1175/1520-0485(1979)009<1155:OTEOIN>2.0.CO;2.

Morrow, R., F. Birol, D. Griffin, and J. Sudre, 2004: Divergent pathways of cyclonic and anti-cyclonic ocean eddies. Geophys. Res. Lett., 31, L24311, https://doi.org/10.1029/2004GL020974.

Penven, P., V. Echevin, J. Pasapera, F. Colas, and J. Tam, 2005: Average circulation, seasonal cycle, and mesoscale dynamics of the Peru current system: A modeling approach. J. Geophys. Res., 110, C10021, https://doi.org/10.1029/2005JC002945.
Rhines, P. B., 1975: Waves and turbulence on a beta-plane. J. Fluid Mech., 69, 417-443, https://doi.org/10.1017/S0022112075001504.

Richardson, P. L., 1983: Eddy kinetic energy in the north Atlantic from surface drifters. J. Geophys. Res., 88, 4355-4367, https:// doi.org/10.1029/JC088iC07p04355.

Roach, C. J., D. Balwada, and K. G. Speer, 2016: Horizontal mixing in the Southern Ocean from Argo float trajectories. J. Geophys. Res. Oceans, 121, 5570-5586, https://doi.org/10.1002/2015JC011440.

— _ — , and —_, 2018: Global observations of horizontal mixing from Argo float and surface drifter trajectories. J. Geophys. Res.Oceans, 123, 4560-4575, https://doi.org/ 10.1029/2018JC013750.

Samelson, R. M., M. G. Schlax, and D. B. Chelton, 2016: A linear stochastic field model of midlatitude mesoscale variability. J. Phys. Oceanogr., 46, 3103-3120, https://doi.org/10.1175/ JPO-D-16-0060.1.

- D. B. Chelton, and M. G. Schlax, 2019: The ocean mesoscale regime of the reduced-gravity quasigeostrophic model. J. Phys. Oceanogr., 49, 2469-2498, https://doi.org/10.1175/ JPO-D-18-0260.1.

Souza, J. M. A. C., C. de Boyer Montégut, C. Cabanes, and P. Klein, 2011: Estimation of the Agulhas ring impacts on meridional heat fluxes and transport using ARGO floats and satellite data. Geophys. Res. Lett., 38, L21602, https:/doi.org/ 10.1029/2011GL049359.

Theiss, J., 2004: Equatorward energy cascade, critical latitude, and the predominance of cyclonic vortices in geostrophic turbulence. J. Phys. Oceanogr., 34, 1663-1678, https://doi.org/ 10.1175/1520-0485(2004)034<1663:EECCLA > 2.0.CO;2.

Tulloch, R., J. Marshall, and K. S. Smith, 2009: Interpretation of the propagation of surface altimetric observations in terms of planetary waves and geostrophic turbulence. J. Geophys. Res., 114, C02005, https://doi.org/10.1029/2008JC005055.

Xu, C., X. Zhai, and X. Shang, 2016: Work done by atmospheric winds on mesoscale ocean eddies. Geophys. Res. Lett., 43, 12 174-12 180, https://doi.org/10.1002/2016GL071275.

Zhai, X., H. L. Johnson, and D. P. Marshall, 2010: Significant sink of ocean-eddy energy near western boundaries. Nat. Geosci., 3, 608-612, https://doi.org/10.1038/ngeo943.

Zhang, Z., W. Wang, and B. Qiu, 2014: Oceanic mass transport by mesoscale eddies. Science, 345, 322-324, https://doi.org/10.1126/ science. 1252418 